\title{
DNA methylation aging clocks: challenges and recommendations
}

\author{
Christopher G. Bell ${ }^{1^{*}}\left(\mathbb{D}\right.$, Robert Lowe ${ }^{2^{*}}$, Peter D. Adams ${ }^{3,4^{*}}$, Andrea A. Baccarelli ${ }^{*}$, Stephan Beck ${ }^{6^{*}}$, Jordana T. Bell $7^{7^{*}}$, \\ Brock C. Christensen ${ }^{8,9,10^{*}}$, Vadim N. Gladyshev ${ }^{11^{*}}$, Bastiaan T. Heijmans ${ }^{12^{*}}$, Steve Horvath ${ }^{13,14^{*}}$, Trey Ideker ${ }^{15^{*}}$, \\ Jean-Pierre J. Issa ${ }^{16^{*}}$, Karl T. Kelsey ${ }^{17,18^{*}}$, Riccardo E. Marioni ${ }^{19,20^{*}}$, Wolf Reik ${ }^{21,22^{*}}$, Caroline L. Relton ${ }^{23^{*}}$, \\ Leonard C. Schalkwyk ${ }^{24^{*}}$, Andrew E. Teschendorff ${ }^{25,26^{*}}$, Wolfgang Wagner ${ }^{27^{*}}$, Kang Zhang ${ }^{28^{*}}$ and \\ Vardhman K. Rakyan ${ }^{2 *}$
}

\footnotetext{
*Correspondence: c.bell@qmul.ac.uk; rlowe.compbio@gmail.com; padams@sbpdiscovery.org; ab4303@cumc.columbia.edu; s.beck@ucl.ac.uk; jordana.bell@kcl.ac.uk; brock.christensen@dartmouth.edu; vgladyshev@rics.bwh.harvard.edu; b.t.heijmans@lumc.nl;

shorvath@mednet.ucla.edu; trey.ideker@gmail.com; jpissa@temple.edu; karl_kelsey@brown.edu; riccardo.marioni@ed.ac.uk; wolf.reik@babraham.ac.uk; caroline.relton@bristol.ac.uk; Ischal@essex.ac.uk; a.teschendorff@ucl.ac.uk; wwagner@ukaachen.de; kang.zhang@gmail.com; v.rakyan@gmul.ac.uk 'William Harvey Research Institute, Barts and The London School of Medicine and Dentistry, Queen Mary University of London, London, UK

${ }^{2}$ The Blizard Institute, Barts and The London School of Medicine and Dentistry, Queen Mary University of London, London, UK

${ }^{3}$ Sanford Burnham Prebys Medical Discovery Institute, La Jolla, CA, USA

${ }^{5}$ Department of Environmental Health Sciences, Mailman School of Public Health, Columbia University, New York, NY, USA

${ }^{6}$ Medical Genomics, Paul O'Gorman Building, UCL Cancer Institute, University College London, London, UK

${ }^{7}$ Department of Twin Research and Genetic Epidemiology, King's College London, London, UK

${ }^{8}$ Department of Epidemiology, Geisel School of Medicine, Dartmouth College, Lebanon, NH, USA

${ }^{11}$ Division of Genetics, Department of Medicine, Brigham and Women's

Hospital and Harvard Medical School, Boston, MA, USA

${ }^{12}$ Molecular Epidemiology, Department of Biomedical Data Sciences, Leiden

University Medical Center, Leiden, the Netherlands

${ }^{13}$ Department of Human Genetics, Gonda Research Center, David Geffen

School of Medicine, Los Angeles, CA, USA

${ }^{15}$ San Diego Center for Systems Biology, University of California-San Diego,

San Diego, CA, USA

${ }^{16}$ Fels Institute for Cancer Research, Lewis Katz School of Medicine, Temple University, Philadelphia, PA, USA

${ }^{17}$ Department of Epidemiology, Brown University, Providence, RI, USA

${ }^{19} \mathrm{Centre}$ for Genomic and Experimental Medicine, Institute of Genetics and

Molecular Medicine, University of Edinburgh, Edinburgh, UK

${ }^{21}$ Epigenetics Programme, The Babraham Institute, Cambridge, UK

${ }^{23}$ Medical Research Council Integrative Epidemiology Unit (MRC IEU), School of Social and Community Medicine, University of Bristol, Bristol, UK

${ }^{24} \mathrm{~S}$ chool of Biological Sciences, University of Essex, Colchester, UK

${ }^{25}$ CAS Key Laboratory of Computational Biology, CAS-MPG Partner Institute for Computational Biology, Shanghai Institute of Nutrition and Health, Shanghai Institutes for Biological Sciences, University of Chinese Academy of Sciences, Chinese Academy of Sciences, 320 Yue Yang Road, Shanghai 200031, China

${ }^{27} \mathrm{Helmholtz-Institute} \mathrm{for} \mathrm{Biomedical} \mathrm{Engineering,} \mathrm{Stem} \mathrm{Cell} \mathrm{Biology} \mathrm{and}$ Cellular Engineering, RWTH Aachen Faculty of Medicine, Aachen, Germany

${ }^{28}$ Faculty of Medicine, Macau University of Science and Technology, Taipa, Macau

Full list of author information is available at the end of the article
}

\begin{abstract}
Epigenetic clocks comprise a set of $\mathrm{CpG}$ sites whose DNA methylation levels measure subject age. These clocks are acknowledged as a highly accurate molecular correlate of chronological age in humans and other vertebrates. Also, extensive research is aimed at their potential to quantify biological aging rates and test longevity or rejuvenating interventions. Here, we discuss key challenges to understand clock mechanisms and biomarker utility. This requires dissecting the drivers and regulators of age-related changes in single-cell, tissue- and disease-specific models, as well as exploring other epigenomic marks, longitudinal and diverse population studies, and nonhuman models. We also highlight important ethical issues in forensic age determination and predicting the trajectory of biological aging in an individual.
\end{abstract}

\section{Introduction}

A key question in biology is to understand why and how we age. Alongside this, the unprecedented gain in the average lifespan in humans, since the mid-twentieth century, has dramatically increased both the number of older people and their proportion in the population. This demographic phenomenon is changing our societal make-up, from only $\sim 130$ million being 65 years or older ( $\sim 5 \%$ of the world population) in 1950 , to a predicted $\sim 1.6$ billion people $(\sim 17 \%)$ by 2050 [1]. However, the success in reducing mortality has not been matched with a reduction in chronic disease [2]. This leads to the undesirable outcome of many years of this prolonged lifespan being spent in ill health, with an associated massive health care burden. Increasing the productivity and reducing the disease affliction in these extended years7

(c) The Author(s). 2019 Open Access This article is distributed under the terms of the Creative Commons Attribution 4.0 International License (http://creativecommons.org/licenses/by/4.0/), which permits unrestricted use, distribution, and reproduction in any medium, provided you give appropriate credit to the original author(s) and the source, provide a link to the Creative Commons license, and indicate if changes were made. The Creative Commons Public Domain Dedication waiver (http://creativecommons.org/publicdomain/zero/1.0/) applies to the data made available in this article, unless otherwise stated. 
would be clearly beneficial for both the individual and society $[2,3]$. This aim of maximizing the "healthspan" [2] makes obtaining accurate measures of aging-related pathology essential, to gauge its speed, decipher the changes that occur, and potentially unlock how aging acts as a disease risk factor [4]. There is considerable population variation in the rate at which people visibly age [5] as well as become impaired by age-related frailty and disease [2]. Measurement of this relative "biological" aging [2] may allow pre-emptive targeted health-promoting interventions, perhaps in a personalized and disease-specific fashion. It would also aid in testing interventions that attempt to modulate the aging process [6].

The cellular and molecular hallmarks of aging include changes associated with cell senescence, dysregulated nutrient sensing, and stem cell exhaustion, among others [6]. Therefore, many biological measures, such as p16 ${ }^{\text {ink4a }}$ tissue levels, circulating CRP, creatinine, and fasting glucose, as well as telomere length all correlate with aging [6-8]. In this decade, we have discovered the remarkable power of epigenetic changes to estimate an individual's age $[9,10]$. Epigenetics encapsulates the chemical modifications and packaging of the genome that influence or indicate its activity [11], with strict definitions requiring inheritance through mitotic cell division [12]. Observations of age impacting on this mechanism have been reported for more than 50 years [13-16] and suggested a role in age-related disease [17]. However, the association between epigenetic modifications and age became most starkly apparent with the arrival of the first high-throughput arrays measuring DNA methylation [18-20]. These high-resolution data enabled the construction of extremely accurate age estimators, termed "Epigenetic" or "DNA methylation clocks" [21-25]. Subsequently, these clocks were reported to capture aspects of biological aging and its associated morbidity and mortality [26-29]. DNA methylation (5'methylcytosine, $5 \mathrm{mC}$ ) is the most common DNA modification and predominantly occurs at cytosines in a $\mathrm{CpG}$ dinucleotide context in differentiated mammalian cells. The stability of $5 \mathrm{mC}$ in biological samples, even from long-term stored DNA, brings large-scale data availability, for use in subsequent high-throughput analysis.

In this paper, we discuss the scientific challenges that the fascinating discovery of "DNA methylation clocks" has brought into focus. We provide recommendations and suggest future experiments required to dissect the strengths and weaknesses of this important biomarker, in order to probe its biological significance, cellular mechanics, and epidemiological potential. We do not review in depth the background history and current state of the clocks themselves; we refer readers to recent excellent reviews for this information $[9,10]$. Instead, the purpose is forward-focused, i.e., to define the current issues, to suggest what will aid unlocking future potential, and to further explore and define any functionality, with the hopeful long-term benefit of increasing the "healthspan."

Here, we define a "DNA methylation clock" as an estimator built from epigenetic DNA methylation marks that are strongly correlated $(r \geq 0.8$ [9]) with chronological age or time, which can accurately quantify an age-related phenotype or outcome, or both. These DNA methylation clocks are generally built with a supervised machine learning method, such as a penalized regression (e.g., lasso or elastic net) trained against chronological age to identify an informative and sparse predictive set of CpGs $[9,10]$. The residual, or error from chronological age, is used as a marker for biological age of an individual $[9,10]$. The agerelated phenotype or outcome may be disease, mortality, clinical measures of "frailty," or cellular phenotypes, including the mitotic age (the total number of lifetime cell divisions of a tissue [30, 31]).

It is evident, even from our initial observations so far, that the aging-related epigenetic modifications captured by DNA methylation clocks are pervasive and indicative of genomic, cell biology, and tissue changes occurring over the life-course. These molecular alterations may bring a high-resolution and precise understanding of age-related pathology and physiology.

\section{Challenge 1 \\ Delineation of the chronological and biological components of DNA methylation clocks Current knowledge}

DNA methylation-derived epigenetic clocks are currently better in estimating actual chronological age than transcriptomic and proteomic data, or telomere length [7]. However, it was recognized that some variability in these initial clocks' age estimation existed, which was identified to be a measure capturing individual variation in biological age. Age acceleration, defined as the difference between this epigenetically measured age and the actual chronological age, was associated with mortality [26] and other age-related phenotypes or diseases [32-39].

Of the first-reported clocks, the Hannum et al. clock was trained and tested on blood-derived DNA [23]. It comprises $71 \mathrm{CpG}$ selected from the Illumina 450k array that strongly capture changes in chronological age, which is partly driven by age-related shifts in blood cell composition [23]. The Horvath clock was constructed across multiple tissues, including the blood data from Hannum et al., as a potential "pan-tissue" master clock of chronological age, and focused on capturing shared changes, independent of tissue type [24]. It included $353 \mathrm{CpGs}$ that were present on the earlier generation Illumina $27 \mathrm{k}$ array. These differences in training sets led to some conflicting findings between reported associations $[7,29,40]$. 
Aging leads to epigenetic alterations, including changes in DNA methylation, through both multiple distinct and intersecting age-related mechanisms [6, 41]. Many DNA methylation aging clocks have now been derived, and due to their individual strengths and weaknesses, explicit reference must be made to the specific clock employed (see further in "Challenge 2"). Captured age-related epigenetic variation can be firstly split into intrinsic, or intra-cellular, and extrinsic, or broadly within-tissue and external, aspects of the aging process [27]. The former is a surrogate readout of multiple cellular and genomic processes, including possible deterioration of mechanisms involved in maintaining the epigenome, while the latter includes agerelated cell proportion changes within a tissue. While these first clocks are markers capturing these effects to a greater or lesser extent [42], both can predict all-cause mortality at a population, but not individual level, even after correcting for known risk factors [27]. To investigate biological age more directly, clocks have also been trained on age-related and disease phenotypes in combination with chronological age, such as the "PhenoAge" DNA methylation clock that incorporates nine age-related biochemical measures [43]. Cigarette smoking, a significant disease-related factor, is observed to strongly drive mortality-associated predictive DNA methylation changes [44]. However, these tobacco-related methylation changes do not influence the Horvath or Hannum et al. clocks, but are captured in "PhenoAge" [9]. Of note, a very recently constructed mortality predictive DNA methylation clock, termed "GrimAge," directly incorporates smoking-related changes through an estimate of "pack-years" smoking. This clock also includes certain plasma protein levels estimated by DNA methylation, and this leads to an even stronger prediction of both lifespan and healthspan [45].

\section{Current uncertainty}

The first DNA methylation clocks devised were found to be useful for estimating actual age, as well as capturing associations with biological aspects of aging. Data gathered from these early clocks can still be exploited for both these chronological and biological measures. However, now this duality has been recognized, we can attempt to improve our assessment of these two characteristics. Specialized clocks are likely to be more powerful for accurate age prediction or to capture specific biological aging-related functional deterioration or disease-related predictions [45]. How far these two distinct uses can be separated into discrete clocks and improved for their specific role is presently unknown. However, clearly if the DNA methylation clock measurement of actual age was perfect, the loss of any variability removes the window where biological aging associations can be made [46]. Empirical calculations estimate that near-perfect forensic age determination may be possible with large enough sample size, even with current
DNA methylation array platforms (see Fig. 1a) [46], although this statistically derived view that chronological clocks can approach extreme precision is not held by all in the field.

Each DNA methylation clock that is constructed is unique to its method of calibration [47], indicating the importance of tissue/s employed, number of samples, and statistical methodology. Clearly, small sample sizes are more susceptible to multiple aging-related confounders, measurement errors, and imperfect statistical predictions. Even when clocks are directly trained on actual chronological age, the strong influence of agerelated biological processes may skew the CpGs selected for the clock, underscoring the importance of an appropriate population of sample donors. Furthermore, as discussed in "Challenge 3," Zhang et al. recently highlighted the impact of not only sample size but also cell type correction, in heterogeneous cell type-derived DNA, on improving chronological age prediction [46].

For "Biological" clocks, another obvious area of uncertainty is that there is not one measure or "gold standard" of biological aging $[6,7,41,48]$. This phenomenon encompasses a wide range of age-associated changes from the merely visible to disease-risk related. To understand how aging may be characterized by chronological and biological age-related epigenetic changes, we need more detailed understanding of what mechanisms may be underlying these observations. There is no evidence that the Horvath or Hannum et al. clock CpGs are enriched for functionality over and above the promoter-focused arrays from which they were constructed. Furthermore, the clocks have shown variability in their ability to capture measures of mitotic age, such as telomere length $[9,49]$, due to their differing training models. In general, epigenetic aging is distinct from senescence-mediated aging and is not prevented by telomerase expression [50-52]. A recent DNA methylation telomere clock identified that although this clock was trained on telomere length, it more strongly reflected cell replication and, moreover, associated with aging-related phenotypes more strongly than telomere length itself [53].

\section{Future experiments and recommendations}

Understanding the chronological and biological drivers of these DNA methylation clocks will require them to be teased apart as much as possible (see Fig. 1b). The clear separation between these two factors, down to specific sets of CpGs, would lead to more powerful specialized clocks and distinct mechanistic studies.

To obtain the most precise estimate of actual age and quantification of its robustness from easily assessable DNA requires appropriately powered large-scale DNA methylation analyses. This is especially the case if this measure is to be used as a legal measure of human age 

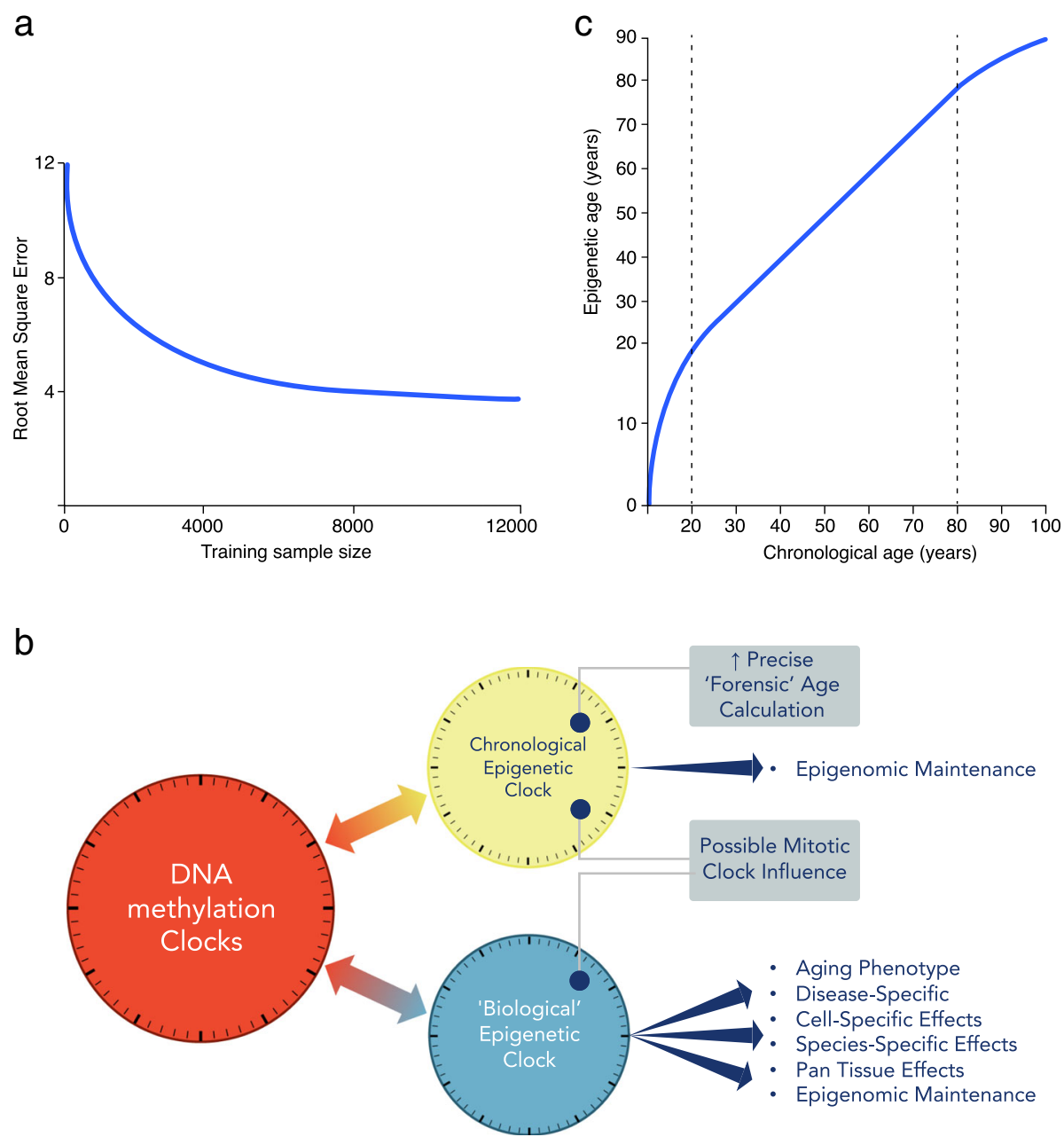

Fig. 1 a Chronological age estimation error. With increasing training sample size, improved measurement of chronological age is expected, even using current array data (adapted from Zhang et al. [46]). y-axis: root mean square error (RMSE) of the predicted age. b DNA methylation clocks contain both chronological and biological information. The relative proportions of each will depend on the CpG probes employed in the construction of the clock. Therefore, there are multiple clocks that can be deconvoluted from aging-related epigenetic changes. Moving forward, more precise chronological (forensic age clock) and biological clocks, specific for particular diseases, informative of health or disease state need to be defined and separated. $\mathbf{c}$ Epigenetic age trajectory. Epigenetic age is not linear over the life course. Chronological age in years ( $x$-axis) and epigenetic age in years ( $y$-axis)

[54-57]. Testing across the range of routinely collected DNA samples will be needed, such as those gathered from peripheral blood or buccal swabs, but also other sources of DNA, such as hair root, skin, and other tissues. However, this is currently only likely to be tractable in data derived from peripheral blood, as these are available at large scale. For the other tissues, the approach is likely to be insufficiently powered in the intermediate future. Specific CpGs will be selected to construct clocks for highprecision forensic age estimation, when chronological age is not known or disputed. They will employ those CpGs that are the most robust and accurate for particular tissues and their constituent cell types [58]. We will need to define the influence of genetic variation and environmental factors on these measures. Accumulating this knowledge of the various DNA methylation clocks will guide their future legal or forensic application [59].

The biological aging component captured by epigenetic age acceleration consists of a large range of drivers, including tissue-specific, cellular aging pathology, stochastic deterioration, and disease-related factors. As mentioned, there is no single measure of biological age; therefore, specific components of aging biology should be focused on and interrogated. This includes aging-related biological pathways involving, for example, mTOR, IGF-1, and p53 [6], as well as epigenomic aspects including the polycomb repressive complex, TET/DNMT levels, and H3K36 methylation $[60,61]$ (see Table 1). This refined analysis could bring new molecular mechanistic insight to the aging process. 
Tissue-specific clocks have the potential to be highly clinically useful as prognostic and diagnostic markers of disease, as discussed in the following "Challenge 2." However, we should not forget about the potentially intriguing insights into aging biology that could be identified by modifications that occur across all tissue types in the body, or pan-tissue changes [62]. Strong outlier candidates for pan-tissue changes identified to date should be further evaluated, such as DNA hypermethylation in ELOVL2, as well as looking for novel aging-related chromatin marks. To confirm any consistency of changes across tissue types will ultimately require large-scale and detailed evaluation of single cell types over time. These points, along with distinguishing the effects of cell type compositiondriven variation in DNA methylation, are discussed in more detail in "Challenge 3" and "Challenge 5" and will all contribute significantly to improved accuracy and understanding of clock-related measures.

\section{Challenge 2}

Functional characterization of tissue-specific and diseasespecific clocks

\section{Current knowledge}

"Biological age" is a large umbrella term for multiple age-related phenotypes and disease processes. Observed disease-related DNA methylation changes will represent the tissue specificity of the particular epigenome, indicative of the mixture of cell types present, as well as the associated organ-specific pathology. While the "sum of parts" Horvath pan-tissue clock is extremely useful, it is unlikely to correspond perfectly to each tissue-specific component. Still, disease-specific aging clocks in easily accessible tissues have high potential for clinical utility as disease-specific monitors and disease risk calculators. However, recognition and identification of those changes that are in fact tissue-specific [63] may also enable improved markers of both chronological and biological age. The benefit of bespoke clocks is seen in the recent "Skin-Blood" clock, devised due to poor performance of the Horvath clock in estimating advanced age in Hutchinson-Gilford progeria syndrome, potentially due to cultured fibroblasts being incorrectly calibrated [64]. In contrast, the "Skin-Blood" clock identified age acceleration in this progeroid disorder with higher sensitivity for these specific tissue types.

Cellular mechanisms, such as mitosis, will vary between tissues and cell types and contribute to changes observed in the epigenome. The DNA methylation state is re-established after replication, but errors occur in the fidelity of this process [65]. Therefore, a methylationbased clock of mitotic age will count cell-specific mitoses. Clocks capturing this process include "epiTOC," which assesses increased DNA methylation in the promoters of Polycomb group target genes that are initially unmethylated in foetal tissues [31]. Replication-associated methylation accelerates in cancer and in pre-cancerous tissue due to carcinogen exposure. Mitotic age also drives the changes observed in the "Remethylated Window Model" with a loss of methylation in specific sparsely located CpGs that reside within partially methylated domains (PMD) [66], the megabasescale late-replicating, lamina-associated hypomethylated blocks [67]. Hypomethylation accumulates with the number of cell divisions, due to relatively slow PMD remethylation, as well as a reduced efficiency in very low $\mathrm{CpG}$ density regions. Cellular damage or inflammatory factors that increase cell turnover led to increased methylation loss [66]. Senescence-related hypomethylation in these regions was also previously proposed to be affected by mislocalization of DNMT1 during the $S$ phase [68]. Additionally, the influence of H3K36me3, which recruits DNMT3B to gene bodies [69], is an independent factor that can act to counter this decrease in DNA methylation. Of note, loss-of-function mutations in the H3K36 histone methyltransferase NSD1 also accelerate the Horvath clock, thus implicating loss of maintenance of this chromatin mark in the DNA methylation changes detected by this clock as well [70].

The developmental stage of the cell can be distinctly observed in clock measures. Additionally, it has been shown that partial and full reprogramming with Yamanaka factors induces a steady decline and a complete resetting of the epigenetic age, respectively [24, 71, 72]. Of note, highly specific CpG methylation changes are observed with replicative senescence and aging in human mesenchymal stem cells [73]. In analogy to the age-associated DNA methylation patterns, the epigenetic modifications during replicative senescence are also reset during reprogramming into induced pluripotent stem cells [74]. In regard to the cellular niche, human hematopoietic cells do not exhibit epigenetic age acceleration upon transplantation into a faster aging species, the mouse [75]. Similarly, the DNA methylation age measurement from hematopoietic stem cell transfusion matches the age of the donor and not that of an older recipient $[76,77]$. In other words, at the resolution of these data, the stem cell niche does not affect the epigenetic age.

Clock-like epigenetic alterations can have disease monitoring utility, even if they are not functional and are only passive changes reflective of underlying biology. However, interesting paradigms exist that may be indicative of broader and more widely applicable pathological mechanisms that connect epigenetic aging and disease. These include examples such as age-related promoter hypermethylation with HAND2 and endometrial cancer [78], as well as Polycomb group target promoters and cancer [18]. Also, the stochastic process of epigenetic drift, which itself actually begins from early age [79, 80], may also play a disease-related role [81]. Age-related DNA methylation modifications disrupt DNA binding patterns of transcription factors (TFs) which regulate the 

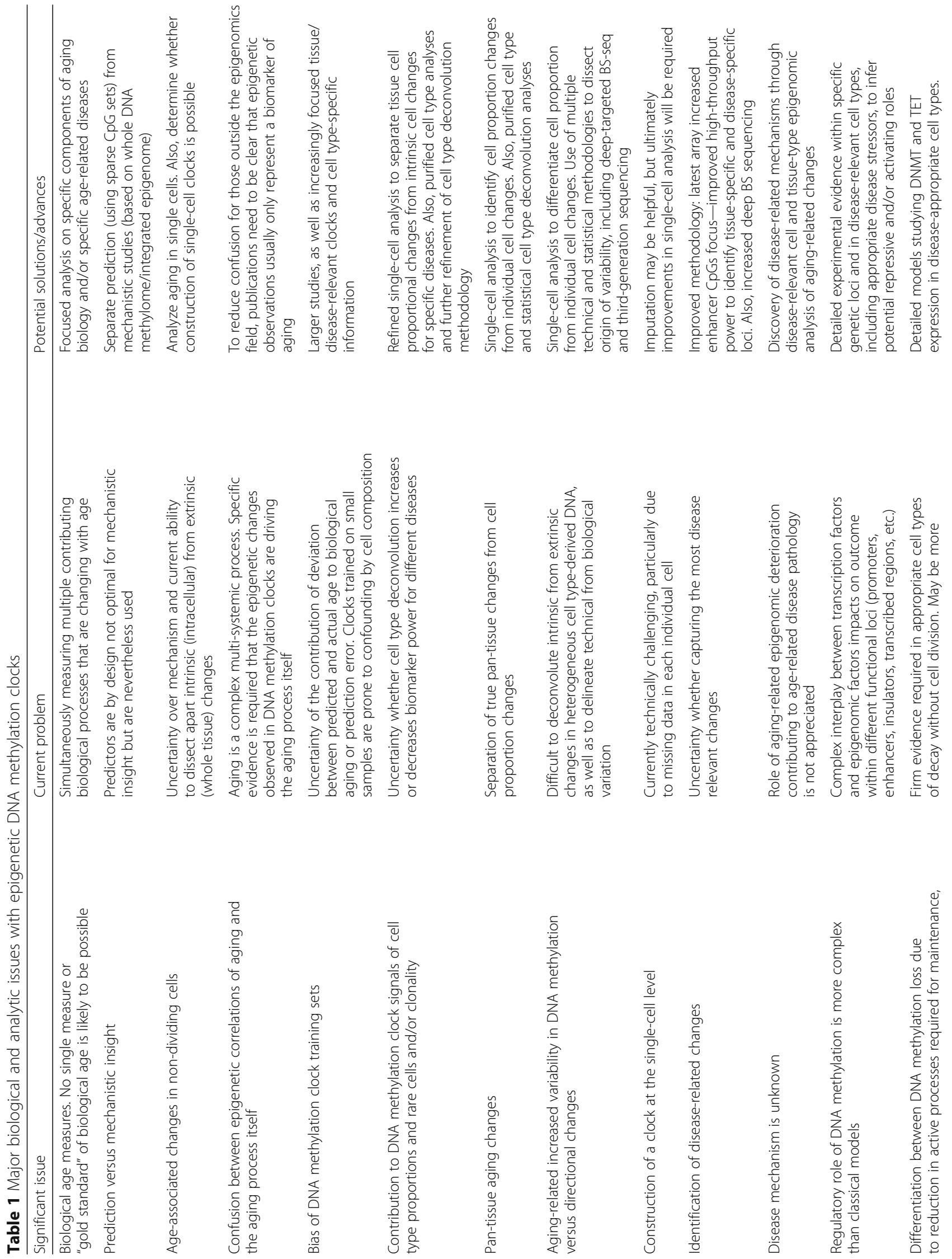

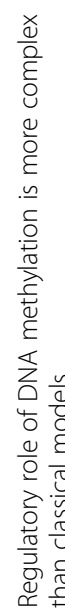

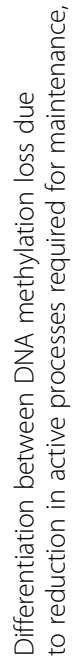


Bell et al. Genome Biology

(2019) 20:249

Page 7 of 24

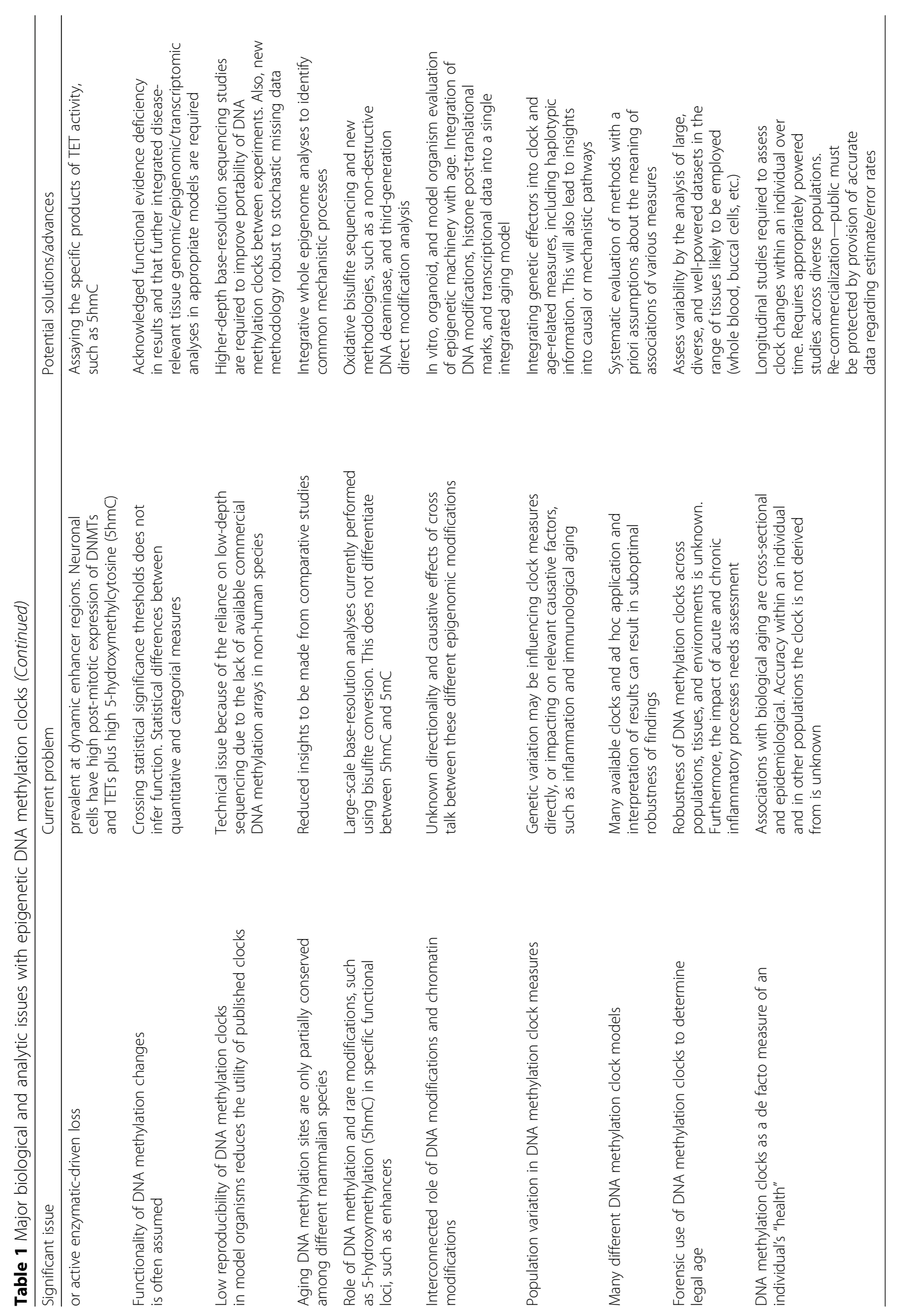


activity of many genes, although currently without strong evidence of expression disruption [82]. Changes with aging have been observed in both the binding sites of the transcriptional repressor REST [83] and insulator CTCF [84]. However, instead of targeting housekeeping or essential genes, epigenetic drift changes tend to occur in the periphery of the protein-protein interactive network [85].

\section{Current uncertainty}

There is uncertainty around how the DNA methylation changes observed in clocks can accrue without replication, i.e., due to processes not related to cell replication (see Table 1). Most tissues are comprised of non- or slowly dividing cells, and different division rates occur in different tissues. Aging-related aberration of the epigenetic machinery is implicated in DNA methylation change over time. However, understanding this will require more detailed characterization of the levels of instability aside from DNA replication, and the extent to which this process is cell-, genetic-sequence-, or cis regulatory element-specific. Cumulative changes, as well as potentially stochastic factors, most likely influence mitotic rate and fidelity, repair, chromatin remodeling, and transcription. These aggregating mechanisms are not exclusive to each other and could be important in differing degrees at different loci or in different cell types. The Horvath clock is derived from a wide variety of tissue types and works across most of them (including sorted neurons) even though these cannot have the same history of cell division, so this clock is not measuring mitosis.

Another point of ambiguity to be acknowledged on the mechanistic side is that epigenetic interaction with TF binding and downstream gene expression is clearly not as simple as usually portrayed in classical models [86]. This complex and significant interrelation between DNA methylation and TFs in various functional elements, such as promoter CpG islands, enhancers, and CTCF loci [87], has revealed experimental evidence supporting not only a negative regulatory role but also in some cases a positive one [88-90].

The use of elastic net regression to construct DNA methylation clocks results in sparse but accurate estimators, with utility in predicting phenotypic outcomes. However, there is uncertainty and limitations in regard to their mechanistic insight, which may instead require more precise knowledge of the specific epigenomic modifiers and transcription factors involved. Age-related hypomethylated $\mathrm{CpG}$ sites are observed to be strongly enriched in enhancer-related loci, in both stem and differentiated cells [91, 92]. Decay through reduced active processes required for maintenance and DNMT and TET-related methylation turnover without cell division is however observed in exit from pluripotency [93]. It is possible that this process may be more prevalent at the most dynamic enhancer regions. Additionally, neuronal cells have revealed high post-mitotic expression of DNMTs and TETs [61, 94], and there are, furthermore, higher levels of 5-hydroxymethylcytosine in the brain [61].

\section{Future experiments and recommendations}

In the hunt for disease- and tissue-specific molecular markers of biological age, future experiments will require individual tissue-, disease-, and mechanismspecific analyses. While clinical utility may be derived from pan-tissue "clocks," such as the Horvath clock, being incorporated into other broad measures such as "frailty" [95], other bespoke "clocks" may be constructed and employed for particular diseases. By directly focusing on clock-like modifications that represent diseaserelated variation in specific tissues, this may bring unique insights and pathophysiological measures. To determine where surrogate tissue can be used, it will be important to establish the level of concordance and discordance between specific tissues within and between individuals [96]. However, this is clearly difficult in more inaccessible tissues. These refined disease-specific clocks may bring improved level of molecular resolution, in evaluating age-related disease progression within an individual. Furthermore, there is potential clinical utility in using a measurement given in "years" to simply explain to patients the concept of complex organ-specific deterioration. Also, these data can be incorporated into prognostic or therapeutic algorithms.

For mechanistic insight, limited CpG clocks in surrogate tissues are unlikely to be highly discerning. Specific CpG tissue and disease-specific clocks will likely capture some aspect of the underlying mechanism but may have less traction than genome-wide or whole-genome approaches. These will have more power to give functional understanding of the drivers of clock-identified changes. However, these currently have their methodological limitations (discussed in "Challenge 4"). For full evaluation, this may require single-cell bisulfite sequencing (scBSseq) studies, nanopore sequencing analysis, and further technological advancement to be fully realized (discussed in "Challenge 5"). These tissue- and disease-specific clocks in isolated cell types or cell type-aware analyses could enable greater insights into the molecular drivers of biological aging [97]. These processes need to be explored across all organ systems, to identify not only specific but also common mechanisms.

Computationally, biophysical models (mathematical simulations of biological systems) need to be explored, as machine learning methods, such as elastic net regression, only offer limited mechanistic insight due to their black box nature. For instance, such biophysical models are beginning to emerge for modeling mitotic age [98], for 
understanding patterns of DNA methylation heterogeneity in aging stem cell populations [99] and for understanding the relationship between age-associated patterns of DNA methylation and alterations in epigenomic regulators [100]. We envisage that future studies that build and improve on these models by explicitly incorporating the latest insights and understanding of epigenomic regulation may be necessary to dissect the inherent complexity of the epigenetic aging process.

As detailed above, this functional interrogation will require the construction of bespoke tissue-specific and disease-specific clocks. However, open-science protocols will need to be followed to maximize their use, as well as their further optimization and improvement. Therefore, the field must require that all clock algorithms are transparent and publicly available to support reproducibility and accelerate progress.

\section{Challenge 3}

Integration of epigenetics into large and diverse longitudinal population studies

\section{Current knowledge}

Longitudinal studies following individuals over the course of their lifetime have considerable advantages in evaluating causal risk factors in disease development. For DNA methylation clocks, these studies are also extremely valuable, as cross-sectional data cannot assess the dynamics of the clock-related changes and measurements over time within an individual. Thus, these analyses can evaluate the relative contributions to epigenetic clock variation, including consistent differences from the start of life, altered trajectories at particular life junctures, such as puberty, or gradual divergence over the entire life-course [9]. Furthermore, the predictive power of clocks for age-related disease can be directly assessed.

The vast majority of epigenetic clock studies to date have been conducted in adults and are cross-sectional in design. The few initial longitudinal analyses performed have seen little variation over epigenetic age acceleration assessment within the same decade [49], and within middle age, multiple clocks track closely [33]. One substantial meta-analysis of longitudinal data from Marioni et al. in five cohorts, comprising 4075 adult participants, identified a slower rate of increase of epigenetic age compared to chronological age with time, with both the Horvath and Hannum et al. clocks [101]. Also, there is a non-linear (logarithmic) pattern in the clock during teenage years $[24,79]$. Therefore, the clock calculation by Horvath included a log-linear transformation for data points from younger individuals. When applied to longitudinal datasets, both the Horvath and Hannum et al. clocks show signs of an asymptote in later life, where chronological age increases at a faster rate than epigenetic estimated age (see Fig. 1c). Cross-sectional studies have also consistently shown strong biological sex differences, with men having greater positive age acceleration than women [102].

\section{Current uncertainty}

The non-linear rate of clock ticking and what may influence this is not precisely defined. The Horvath clock is seen to run the fastest during development, while during adulthood, linear associations are observed with clock years increasing at the same rate as chronological years, on average. The biological aging marker of epigenetic age acceleration assessed from birth shows minimal variation to adolescence and then increases with age [103] and is hypothesized to be influenced by developmental changes during childhood and adolescence [104].

The full extent of genetic influence on DNA methylation both within CpGs on the arrays and further beyond in the genome is still underappreciated [86, 105-108]. How significant and through which pathways genetic influences act on clock longitudinal dynamics is uncertain, but has begun to be explored [109], and further major meta-analyses are in progress. Twin studies estimate that the heritability of the epigenetic age acceleration is relatively high $\left(h^{2} \sim 40 \%\right)$ [9]. This is even higher at younger age, implying, as we age, there is an increasingly environmental contribution to the age acceleration calculation [24]. Of note, a genome-wide association study for the Horvath clock calculated age acceleration identified five loci, including an intronic variant with unknown functional implications within the telomerase reverse transcriptase (TERT) gene [110]. It is still unclear how much deviation of epigenetic age from chronological age is driven by different rates in biological aging or genetically determined differences between individuals. Moreover, various threads of evidence indicate some epigenetic loci display increased variability with age, which may potentially be an important and distinct measure in capturing biological age [111]. This is also observed in longitudinal analysis, with a fraction of these age-varying CpGs identified to be under genetic influence $[109,112]$.

Further areas of uncertainty arose from the longitudinal meta-analysis of Marioni et al. [101]. Firstly, significant differences between the Horvath and Hannum et al. clocks were seen, as would be expected due to their differing tissue training sets. However, they further proposed that while some of the slowing of the clock rate in the elderly may be due to survivor bias, there may also be a plateau to epigenetic clock estimates. Intriguingly, a possible decline at late age has even been postulated [113].

Recently, Zhang et al. identified that correcting for blood cell type proportions attenuated the all-cause mortality associations with both the Horvath and Hannum et al. clocks [46]. This reduction was shown to be greater for clocks built from smaller training sets. Furthermore, 
the association with mortality lessened, even without cell type correction, with increased training set size. The biomarker power of specific clocks may be increased or decreased depending on the contribution of major cell proportions to the specific disease or trait being examined (see Table 1). Changes associated with immunological aging $[114,115]$ are clearly contributing to aspects of biological aging. However, more precision is required regarding how these manifest within individuals over the life-course, as well as which specific cell types drive distinct associations.

\section{Future experiments and recommendations}

Longitudinal studies enable the description of the phenotypic manifestations of aging within individuals [9]. Therefore, they are powerful for determining the predictive ability of the DNA methylation biomarkers of disease and outcomes in individuals. As these studies are generally designed with multiple, often frequent, biospecimen collection, those including early age and young adulthood will be able to query observed departures of predictors from chronologic age through this developmental period. Similarly, samples obtained over multiple timepoints from elderly subjects could address questions about slowing in epigenetically predicted age. The availability of multiple sources of DNA from various tissues over time would also facilitate robust multi-tissue age evaluations [9].

By identifying the best-designed studies, with appropriate tissues, physiological, functional, and molecular biomarkers, and disease monitoring, the relative disease predictive power of DNA methylation can be robustly assessed. Due to the expense, consensus on this investment will help its realization. There has been significant success in genetic studies using the rigorously phenotyped UK Biobank. This is not only through extremely powerful GWAS, but also collating this information into a calculated risk for specific common diseases with genome-wide polygenic risk scores (PRSs) [116] with potential clinical utility [117]. Many well-known cohorts have generated DNA methylation data $[107,118,119]$, but, undoubtedly, it would be highly desirable to assay further powerful longitudinal studies in extremely large datasets of deeply phenotyped individuals. Understanding the dynamics of clock-estimated age will improve as more studies obtain repeated measures of DNA methylation. This could include an application of latent class analysis on categories such as early, late, or constant epigenetic age acceleration.

It would be beneficial to generate DNA methylation data at scale on one or more cohort studies that have (a) prospectively collected data and DNA samples, (b) deep phenotyping of age-related traits, (c) standard biochemical markers of aging-related decline, (d) repeated measures, and (e) genetic data. Given the derivation of human DNA methylation clocks from array-based data, the latest generation DNA methylation array (EPIC 850k) would be the pragmatic approach at the current time. However, the field is currently in transition between a reliance of arraybased platforms that capture data on a small subset of $\mathrm{CpG}$ sites and sequence-based approaches. As noted later (in "Challenge 4"), the interrogation of a wider range of DNA methylation sites using sequence data will ultimately bring added insights into underlying mechanisms, but the cost of such an approach at scale and appropriate depth is currently prohibitive.

The interrelationship between genotype and DNA methylome clock changes could be robustly evaluated in any large epidemiological cohorts that are genotyped (for some, such as UK Biobank, a significant portion is soon to be fully sequenced). Therefore, chronological age estimation could potentially be improved after correcting for identified genetic effectors on this measure. More nuanced haplotypic integration of epigenetic and genetic variation will ultimately be required. It will also be possible to study the impact of how genetic variation can influence clocks driven by relevant causative factors, such as inflammation and immunological aging. The relationship between genotype and DNA methylation clock calculations can be exploited to gain insights into causal or mechanistic pathways. For example, in cohorts where both genotype and DNA methylation data are available, it would be feasible to apply a Mendelian randomization approach to appraise the causal impact of a potential determinant of clock-derived age [120,121]. A hypothesis-free approach might include the application of LD score regression [122], which would use all genetic variants associated with clock age and compare these against all available GWAS data to search for traits that show common genetic architecture with DNA methylation clock age. This may shed light on potential pathways that influence aging.

There is considerable potential clinical utility in the incorporation of epigenetic data in disease prediction. Given the precision with which DNA methylation clock age can be estimated and evolving measures of biological, phenotype-, and disease-related age (e.g., PhenoAge [43], GrimAge [45]), it may be a useful tool in enhancing clinical prediction models of age-related disease incidence. Studies to date have assessed the combined contribution of genetic and epigenetic data to specific traits [123, 124] and have demonstrated the utility of using DNA methylation as an index of specific health-related exposures, notably smoking [125], to predict future disease risk [126]. This ability to use blood-derived DNA methylation as a systemic exposure measure will continue to be refined. Adding clock-derived measures of biological aging to such prediction models could bring enhanced sensitivity and specificity over and above that possible from self-reported measures of known risk factors. For example, 
cardiovascular risk could combine genetic PRS for this trait with GrimAge clock measures, which estimate cardiovascular disease-related risk, such as smoking packyears, plasma beta- 2 microglobulin, and other plasma proteins, and predicts time to coronary heart disease [45].

Regarding the issue of cell type deconvolution for clock association, this will be specific to the disease or trait being examined. Single-cell analysis, as detailed in "Challenge 5," will also help pinpoint which cell type(s) is the most important and guide the use of cell type corrections in heterogeneous DNA samples for larger longitudinal and epidemiological studies.

Another very important issue is that all these genetic and epigenetic data and analyses are strongly biased toward populations of European ancestry and other populations are grossly under-represented. Further large-scale diverse longitudinal studies are imperative [127]. As mentioned, the extent of genetic influence is currently underestimated and will therefore need detailed analysis across multiple populations (see Table 1). Additionally, the unique advantages of monozygotic twin studies should also be borne in mind $[105,128]$, and the comparison of these non-genetically confounded studies with larger population findings may be illuminating. Another fascinating avenue to explore that may reveal novel insights are those contemporary populations worldwide that commonly exhibit extreme longevity, termed "blue zones" [129]. These regions include Nicoya in Costa Rica, Ikaria in Greece, a region of Sardinia in Italy, Okinawa in Japan, and Loma Linda in the USA [2].

\section{Challenge 4}

\section{Genome-wide analyses of aging and exploration of additional epigenomic marks Current knowledge}

The initial DNA methylation clocks in humans were derived from the Illumina $27 \mathrm{k}$ or $450 \mathrm{k}$ DNA methylation arrays available at the time [21,23-25]. Even the latest generation EPIC $850 \mathrm{k}$ only assesses $\sim 850,000$ sites, which is $\sim 3 \%$ of all the $\mathrm{CpG}$ sites in the human genome. However, as aging changes are pervasive throughout the DNA methylome, these arrays easily capture age-related variation [23]. Only a small number of $\mathrm{CpG}$ sites are required in the clocks (i.e., Horvath: 353, Hannum et al.: 71, PhenoAge: 513, epiTOC: 385). The distribution of these selected CpGs, compared to genomic functional regions, can be seen in Fig. 2a-e and is clearly enriched for active loci (such as transcription start site/promoter regions) due to the available $\mathrm{CpGs}$ for selection present on the arrays. Within the DNA methylome itself, the likelihood of methylation variability at an individual CpG is associated with its surrounding CpG density [134], with intermediate density regions showing the most changeability through development, across tissue types, and in cancer $[135,136]$. The proportion of variable sites (methylation change $\sim 20.3$ ) in normal conditions is estimated at $15-21 \%$ [137, 138] (see Fig. 2f and g for transcript as well as $\mathrm{CpG}$ island and shore distribution of clock probes, respectively).

The association between other DNA modifications and age in humans remains underexplored. Aging-related changes have been seen with hydroxymethylation $(5 \mathrm{hmC})$, even in blood, where this modification is infrequent [139]. More detailed analysis is required to assess whether this approaches the correlation identified for $5 \mathrm{mC}$. Extensive chromatin changes with age are observed in model organisms (yeast, worms, flies, and mice) [140]. The co-ordinated nature of the epigenomic machinery through both chromatin modifications and DNA methylation [141, 142], as well as experimental evidence from chromatin regulators, such as DOTL1 [143], implies that aging chromatin clocks could also exist, although without the ease of assay and highly quantitative measurements that DNA modifications enable. Broad chromatin aging-related changes include loss of H3K9me3 within heterochromatin and redistribution of H3K4me3 and H3K27me3 in euchromatin [60]. Additionally, aging in a mouse brain leads to altered hippocampal chromatin plasticity with deregulation of histone $\mathrm{H} 4$ lysine 12 (H4K12) acetylation [144], as well as histone variant H2A.Z accumulation [145]. In human prefrontal cortices, aging-related changes were found in $\mathrm{H} 3 \mathrm{~K} 9$ acetylation (H3K9ac) associated with Alzheimer's-related tau protein burden [146].

\section{Current uncertainty}

In regard to the DNA methylome, few sequencing-based studies have investigated regions beyond the limited CpGs profiled using array-based techniques [147-149]. The question is how much more information can we obtain by examining additional sites in the epigenome, what additional value this will bring, and where should we look? Sequencing-based studies will easily observe aging changes, but are expensive to perform, especially with whole-genome base-resolution techniques, and suffer from inconsistent regional coverage, making use of common clocks problematic. Furthermore, higher levels of coverage $(\sim 100 \mathrm{X})$ than typically employed (5-30X) are actually required to call high-confidence differentially methylated positions (DMPs) [150]. Of note, Horvath's pan-tissue clock exploits the $27 \mathrm{k}$ array and is highly accurate in predicting chronological age even without including the ELOVL2 CpGs covered with the 450k array, which display age associations that are much stronger, and consistent across tissues, than any other CpG currently identified [46].

An additional question is whether we can glean new information about biological aging and not just a more accurate chronological clock. Repetitive elements, such 


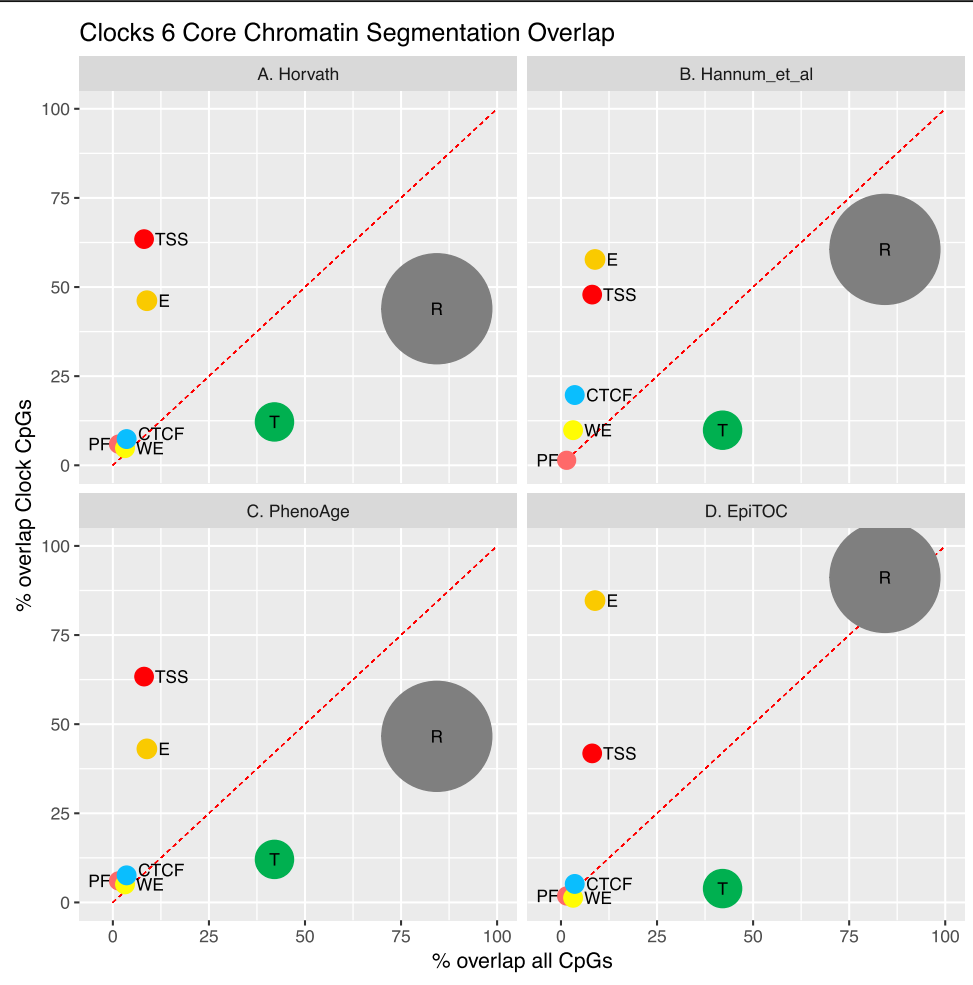

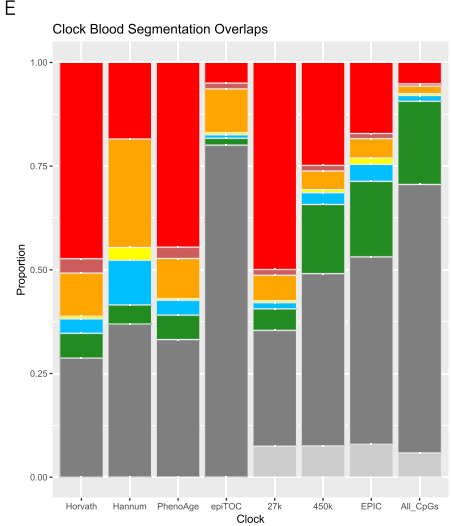

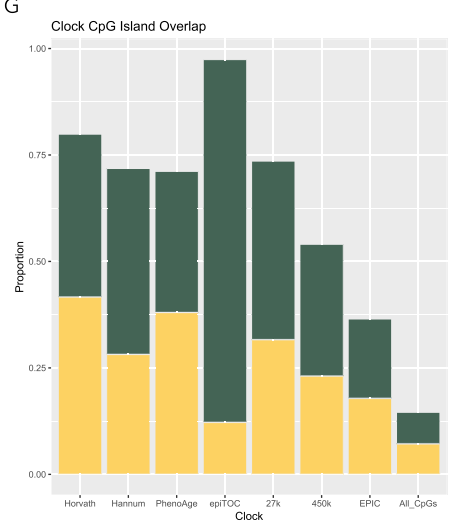

Clock Transcript overlap

$\boldsymbol{P}_{\mathrm{PF}}^{\mathrm{TsS}}$

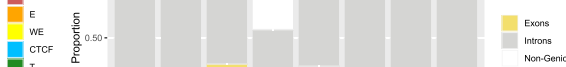

$\boldsymbol{B}_{\mathrm{R}}^{\mathrm{T}}$
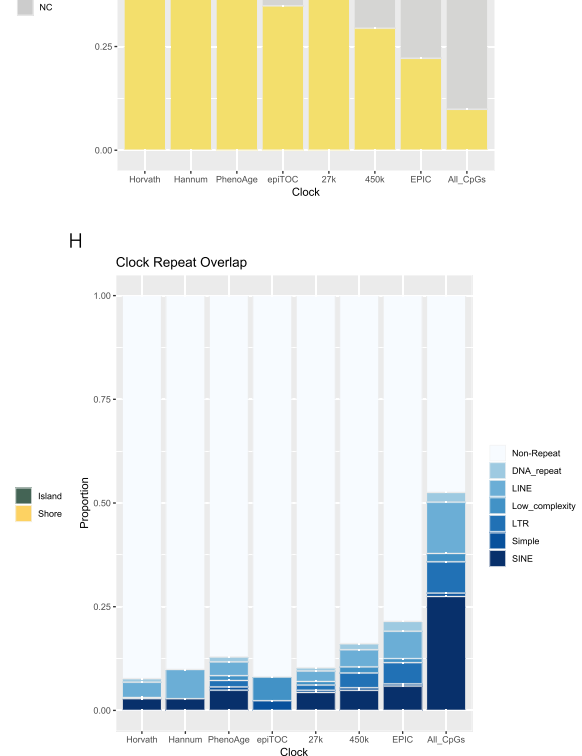

Fig. 2 (See legend on next page.) 
(See figure on previous page.)

Fig. 2 All clock probes are strongly biased to reside within active functional loci. This is due to their construction from promoter-focused arrays. Overlap of CpGs from four DNA methylation clocks with the six Core Encode Combined Chromatin Segmentation tracks [130] from ENCODE Analysis Data at UCSC. a Horvath clock [24]. b Hannum et al. clock [23]. c PhenoAge clock [43]. d epiTOC clock [31]. Location is assessed for overlap with the seven functional categories: PF (promoter flanking - light red), TSS (transcription start site and promoter region—red), CTCF (blue), WE (weak enhancer-yellow), E (enhancer-gold), T (transcribed region-green), and R (repressed-grey), from any of the six Core Encode cell types (Gm12878, H1hesc, Helas3, Hepg2, Huvec, K562). This percentage overlap is shown on the $y$-axis and is compared with the percentage overlap for all $\sim 28 \times 10^{6} \mathrm{CpGs}$ in the human genome on the $x$-axis. Calculated via bedtools [131]. The size of the circle is proportional

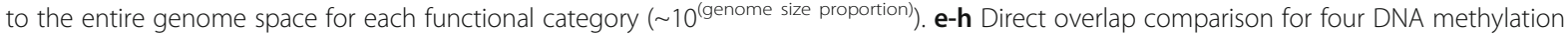
clocks (Horvath clock, Hannum et al. clock, PhenoAge clock, epiTOC clock) as well as Illumina array CpGs (27k, 450k, EPIC) and all genomic CpGs (far right bar) with: e the Combined Segmentation track for blood-derived tissue (GM12878) [130]. Functional segments are delineated as PF (promoter flanking), TSS (transcription start site and promoter region), CTCF, WE (weak enhancer), E (enhancer), T (transcribed region), and R (repressed). NC, not covered CpGs in this Combined Segmentation overlap; $\mathbf{f}$ Gencode [132] Exon and Transcripts; $\mathbf{g}$ UCSC [133]-defined CpG islands and shore regions (+/-2 kb); $\mathbf{h}$ Major repeat classes (UCSC RepeatMasker [133]), including DNA repeat elements (DNA_repeats), long interspersed nuclear elements (LINE), low complexity repeats and other rare repeat classes, long terminal repeat elements (LTR), simple repeats (microsatellites aka short tandem repeats), and short interspersed nuclear elements (SINE), of which $\sim 63 \%$ are Alu elements

as SINE (predominately Alu elements in humans), LINEs, and LTRs, of the genome could be responsive to environmental factors such as diet and stress, and as such are intriguing targets for further exploration [151]. Repetitive regions possess latent functionality [152, 153], however are robustly epigenetically repressed by DNA methylation $[151,154,155]$. Their hypomethylation with age could, therefore, be a significant underexplored pathogenic mechanism in non-malignant age-related disease. An early whole-genome bisulfite sequencing (WGBS) neonate versus centenarian comparison identified $\sim 87 \%$ of the differentially methylated regions (DMRs) to be losing methylation with age [147]. Although changes in cell composition were not accounted for, it was still interesting to note that strong enrichment occurred in repetitive sequence, with $\sim 18 \%$ of the age DMRs in Alu elements. The impact of this deterioration of their epigenetic state with age is however uncertain, and, furthermore, these repetitive elements are largely not represented on arrays for technical reasons. For example, only $\sim 2.7 \%$ of the $450 \mathrm{k}$ array probes overlap Alu elements, and this small fraction is $\sim 4 \mathrm{x}$ more likely to be from the recognized set of technically poor functioning probes [156]. Also, further unknown age-related pathology may exist with other repeat families, including the LTR12C subfamily of LTR repeats that possesses significant enhancer evidence in multiple tissues in humans [157]. While earlier targeted work was not strongly supportive of age-related promoter hypermethylation being due to adjacent or overlapping repeats [158-160], latent enhancer hypomethylation with age is another possibility [92]. Hypotheses proposed for the mechanism involved in DNA methylation loss within these loci include inadequate DNA methylation maintenance influenced by a lack of dietary substrates, such as those for $S$-adenosylmethionine (SAM) [81], or TET-mediated active DNA demethylation [161]. Interestingly, an assessment of the human DNA methylation clocks found that CpGs reducing in their methylation level with age, rather than those gaining methylation, were the most indicative of biological aging through their association with life expectancy [162].

A further key question is how interconnected across the entire genome are all these age-associated epigenetic changes and whether there are specific altered "hubs" which drive concerted changes at both the DNA and the histone modification level. If epigenetic drift could affect activity of one of these hubs, and likelihood of this happening may well increase with age, then drift could have a functional impact. The endpoint gain or loss of defined functional units, such as a specific enhancer, proposes that aging chromatin clocks could be more informative or sensitive. Furthermore, these epigenomic changes would be tractable for exploration in those model organisms that lack DNA methylation (e.g., yeast and C. elegans).

\section{Future experiments and recommendations}

There are several considerations for the next wave of studies into the biology of aging. First, analyzing a large number of samples is key (see "Challenge 3"), ideally in the 1000s. Over the course of the next few years, it is unlikely that any technology will be able to do this affordably at base resolution other than the current generation of Illumina EPIC 850k DNA methylation arrays. Therefore, at this point in time, large-scale populationbased studies of the aging epigenome will continue with this robust array. Many of the additional sites on the platform may not provide any further independent information, although with the caveat that increased enhancer loci have been explicitly targeted on this array. This increased focus on enhancer CpGs potentially gives this array improved power to identify tissue-specific and disease-specific loci. Another possibility is a two-stage study design with the first step involving adequately powered WGBS to gain greater coverage to identify agevariable DNA methylation sites and regions, then 
designing a custom array that could be used at very low cost on very large numbers.

While the focus so far has been on DNA methylation, other DNA modifications, as well as known and currently unrecognized chromatin modifications, should be explored and may reveal exciting clock-like properties. Suggestively, the premature autosomal recessive aging disorder, Werner syndrome, while showing DNA methylation clock age acceleration [163], also has identified significant heterochromatin changes [164]. The optimum analysis of chromatin modifications requires fresh samples, but epigenome-wide association studies have been recently performed successfully with histone acetylation derived from post-mortem specimens [165]. These data can also be further integrated with DNA modification changes. Larger scale mass spectrometry quantitation of histone modifications could also be evaluated. Additional DNA modification analysis by oxidative BS-seq via array for $5 \mathrm{hmC} \mathrm{[166]} \mathrm{should} \mathrm{be} \mathrm{further} \mathrm{evaluated} \mathrm{in} \mathrm{aging,}$ although this is still currently expensive to perform in large numbers. However, new methodologies, such as a non-destructive DNA deaminase [167], may help to propel these on.

Repetitive elements, where currently technically possible, may be sites for identifying aging-associated DNA modification in order to construct novel clocks, and these loci are clearly under-represented by arrays presently (see Fig. 2h). In this exploration, smaller scale whole-genome sequencing DNA methylome analyses should not be deterred. Analyzing repetitive elements by these methods is the only realistic option, and for the longer repeats, third-generation direct long-read sequencing may be required. Although they can measure modifications directly, given the sample numbers needed and the error rate in DNA methylation measurements for third-generation technology, such studies are 3-4 years away. However, current second-generation techniques may, despite technical challenges, reveal prospective loci that can then be robustly explored and validated through targeted amplicon BS-seq techniques via platforms such as Fluidigm Access Array [168] or as third-generation direct sequencing matures. Also, classic and novel chromatin marks should be scrutinized for unique clock-like signatures. An important future direction for functional exploration is to connect DNA modifications, histone post-translational marks, and transcriptional data into a single integrated aging model.

\section{Challenge 5}

\section{Single-cell analysis of aging changes and disease Current knowledge}

Novel insights into aging-related biological changes will be identified by moving beyond the misleading homogeneity of bulk-cell-derived data to the heterogeneity of single-cell analysis [169]. Tissues age as both genetic and epigenetic mosaics, changing their cellular variation. This indicates that single-cell analysis will be necessary to accurately understand this process. This may pinpoint individual cell type age DMPs. Significant aging-related cell composition changes are observed in blood, which include a skew toward myeloid lineage-derived cells [170], diminishing immune competence and a shift from naive to memory $\mathrm{T}$ cells [171], and clonal competition [172]. These cell mixture changes occurring with age may be equally complex in other tissue types. In fact, single-cell techniques have recently recognized previously unknown pathologically relevant cell types, for example in the airway epithelium [173]. An important example in the context of aging is sporadic senescent cells that occur in aging tissues, with accumulating evidence that these cells may be a driver in deteriorating organ function [174].

A key question regarding the DNA methylation clock at the single-cell level is to what extent clock site changes are cell autonomous or conversely to what degree the clock is a cell ensemble phenomenon. As most of the age-related changes in DNA methylation are relatively small, it is perhaps more likely that for most clock (or even age-related) sites, the changes observed, even in relatively homogeneous cell populations, are not cell autonomous but rather cell population based. That is, they are occurring only in a subset of cells in a tissue. Singlecell data may bring answers to these questions, as well as insight into aging mechanisms beyond the current predictive power of DNA methylation clocks. Construction of a clock at the single-cell level is currently technically challenging primarily because of missing data in each individual cell. Computational techniques such as imputation may help with these absent values [175]. Nevertheless, findings from single-cell combined transcriptome and DNA methylome sequencing in mouse muscle stem cells have already shown specific contextdependent increases of cell-to-cell heterogeneity in methylation coupled with increased transcriptional heterogeneity, especially in stem cell niche genes [176]. Similarly, chromatin modification analyses in blood, while clearly indicating immune cell types, also identify an increase in cell-to-cell variability with age, or "epigenomic noise," with particular increases in both H3K4me3 and H3K27me3 [177]. This variability is a molecular signature of immune cell aging and may be due to the rise of distinct clones. Twin analysis revealed the majority of the changes (70\%) were non-heritable or environmentally driven, being in a similar range to the $\sim 80 \%$ proposed for DNA methylation changes [107]. On the expression side, single-cell analysis in mice also identified an increase in variability with age, with greater cell-to-cell transcriptional volatility in CD4 T cells [178]. 
Bulk analysis of isolated cell populations can still give epigenetic insights and also hint further at what singlecell analysis will be able to refine with even further cell type or clonal resolution. For instance, in humans, bulk purified CD8 T cells show decreased naive and increased memory sub-fractions [114]. Additionally, ATAC-seq of aging naive cells demonstrated reduced promoter accessibility, especially for the DNA methylation-sensitive transcription factor NRF1 [114]. This is indicative of the integrated epigenomic and transcriptomic changes occurring during aging. On the genetic side, deep exome sequencing has identified age-related clonal hematopoiesis in blood [179] and positively selected clones show prevalent mutations in epigenome-modifying genes, DNMT3A, TET2, and ASXL1 $[179,180]$. These clones are pathogenically associated with not only hematological cancers $[179,180]$ but also non-cancer disease risks such as atherosclerosis [181].

\section{Current uncertainty}

Exploring clock-related changes at the single-cell level would determine the cell type drivers of tissue-specific clocks. However, at this point, a significant unknown is how discrete the epigenomic profile of distinct cell types are and how much of a continuum between cell types exists. Also, what changes are occurring prior to observable age-related changes, such as up-regulation of trans-acting TFs. How do the levels of DNMTs and TETs change, and what is their interaction with other substrates? With the initial Horvath clock, some organs had a larger error in estimation of chronological age [24], initially interpreted as faster biological aging rates, though now thought possibly due to the impact of hormones on tissues such as the breast [182]. While cell isolation techniques may enable robust and insightful studies due to larger sample sizes, their level of resolution may be limited by the methodologies employed and current knowledge of cell categorization [183].

Another area of uncertainty is pan-tissue aging changes. While there is strong indication of significant and perhaps unique outliers that exhibit aging changes across all tissue types [63], such as ELOVL2 [46], analysis of the large number of tissue-specific changes with tissue-specific clocks will bring substantial insight (as discussed in "Challenge 2"). There is evidence for a significant level of shared age DMPs between certain tissues [62], and single-cell analysis will allow for more robust evaluation of both these observations to identify in which individual cells these occur.

Increasing levels of somatic genetic mutation with age are now recognized [184, 185], leading to distinct clones, with potential pathological involvement even in nonmalignant age-related disease [186]. How this may impact in a cell- and disease-specific fashion throughout the epigenome and clock-related changes is another uncertainty in age-related pathophysiology, particularly if a mutational enrichment in epigenome-modifying genes is observed, as in cancer [187].

\section{Future experiments and recommendations}

Single-cell epigenomics will facilitate much more detailed exploration in both disease and age-related changes. While the technology is still evolving, successful datasets have already been produced and are able to give a level of resolution that is beyond previous expectations, with methods such as single-cell ATAC-seq and BS-seq [172]. This allows precise exploration of core epigenomic issues related to cell type heterogeneity and its tissue-specific modification with age. Single-cell analysis has the potential to reveal stronger cell type-specific changes that are currently diluted in signal in present results (see Fig. 3). This will include the identification of novel cell types, accumulation of senescent cells, and clonal competition that will manifest as epigenomic variation associated with age and age-related disease. Additionally, tissue-specific versus pan-tissue common aging findings can be further explored [62]. Single-cell analysis can also probe and more clearly evaluate and subcategorize phenomena observed with bulk analyses, such as increased DNA methylation variability with age [111].

This methodology will also allow dissection of cellular aging changes, such as the clock-like DNA methylation changes related to mitosis $[31,66]$. Cell-specific age DMPs may indicate the binding footprints of specific TFs [87], enabling cell type-specific aging-related mechanisms to be defined. It is likely that with improved

Individual 2
Fig. 3 Single-cell analysis. Distinct cell variation in aging epigenetic
clock changes may exist that would not be apparent in bulk
comparison. Black and white squares represent methylated and
unmethylated loci, respectively. Each row represents a single cell's
epigenome (represented as haploid for simplicity) with increased
variability present in individual 2


coverage of scBS-seq it will be possible to generate a single-cell clock; this may also be aided by further methodological or technical breakthroughs, including potentially single-cell multi-omics measurements [188]. Furthermore, modulation by experimental models may give further insight into the influence of particular substrates in observed aging changes. Data quality is steadily improving, although bulk-derived results are not obsolete and can complement and clarify single cell information due to issues such as non-specific results and reduced depth [172]. As these aging changes are so relevant to the function of cells and organs, we recommend that aging changes need to be clearly considered along, or in conjunction with the Human Cell Atlas initiatives where possible [189]. This will need attention in singlecell aging-related disease studies, and further complexity may exist through the intercellular environment via the influence of neighboring cells on cell aging trajectories.

The technology is rapidly developing, as illustrated by the recent sci-CAR (single-cell combinatorial indexing chromatin accessibility and mRNA) assay, permitting the profiling of both chromatin accessibility and gene expression in thousands of single cells [190]. This and other maturing methodologies [191] will undoubtedly enable more precise understanding of age-related observations such as epigenomic drift. This should eventually enable single-cell epigenetic clocks giving a clearer indication of the functionality of these aging-related changes and guide further future experiments into the mechanism of disease.

\section{Challenge 6}

\section{Generation of robust non-human data of aging Current knowledge}

Much of what we know about the biology of aging comes from studies on model organisms [6]. Taking advantage of all this knowledge, the development of DNA methylation clocks in these experimental systems brings with it an opportunity to advance our understanding of the role of the epigenome in aging. The Horvath clock initially demonstrated a strong correlation with age in our closest relatives: the chimpanzees and bonobos [24]. However, for the common laboratory mouse strains, only $1.6 \%$ of the EPIC array probes aligned to conserved CpG sites [192]. Age-related changes in the DNA methylome have been extensively analyzed in $\mathrm{C} 57 \mathrm{Bl} / 6$ mice. Sziraki et al. described global remodeling of the mouse DNA methylome with age, reporting numerous global, region-specific, and site-specific features [193]. The associated genes and promoters were found to be enriched for pathways associated with aging, suggesting a fundamental relationship between the epigenome and the aging process. In addition, aging was accompanied by an increase in entropy, consistent with damage accumulation. Interestingly, the effects of this entropy varied for the sites that decreased, increased, and did not change DNA methylation levels with age. Some sites trailed behind, whereas some followed or even exceeded the entropy trajectory and altered the developmental DNA methylation pattern. The patterns found in certain genomic regions were also conserved between humans and mice, indicating common principles of functional DNA methylome modulation between species. As this study examined a whole range of mouse ages, it also detected accelerated changes in the DNA methylome in late life, which were not seen in studies with more limited age ranges [159, 194, 195]. Also, calorie restriction both shifted the overall methylation pattern and was accompanied by its gradual age-related remodeling. As in humans, with age, both highly and lowly methylated sites trended toward intermediate levels, and aging was accompanied by an accelerated increase in entropy [23, 41, 193].

A number of successful mouse sequencing-based DNA methylation aging estimators have been devised, including multi-tissue clocks [196-198], a liver clock [199], and a blood clock [200]. Field et al. have also recently described the clear strengths of mouse aging models [10]. One advantage of mouse models is the possibility of testing longevity interventions or modulators. For example, a multi-tissue clock was accelerated by high-fat diet [196], and the liver clock reported the effects of caloric restriction, dietary rapamycin, and Prop $1^{\mathrm{df} / \mathrm{df}}$ dwarfism [199]. The blood-based clock revealed the impact of caloric restriction and dwarfism, as well as the influence of a whole-body knockout of the growth hormone receptor [200]. One of the most recent studies also carried out a comparative analysis of these mouse clocks, noting certain limitations between tissue and multi-tissue estimators [198]. A calorie restriction intervention led to significant changes in epigenetic age in mouse [200], and, furthermore, a $30 \%$ restriction in rhesus macaques led to an average DNA methylation age 7 years lower than chronological age [194]. In addition to the notion that the epigenetic clock sites may be variable in relation to metabolism, an overlap of age-related cytosine modifications with sites that exert epigenetic control of circadian machinery genes has been observed [201]. Wide-ranging mechanistic findings have also been drawn in mice, such as a trans-species experiment with an aneuploid mouse, which possesses a human chromosome 21 within its nucleus, revealing increased agingrelated DNA-methylated changes, implying these are influenced by the cell's nuclear environment [202].

The mouse has emerged as a significant model organism to study and quantify the epigenetic changes with age in a mechanistic way, e.g., the effects of longevity interventions on biological age were first demonstrated in mice. There is no doubt that further improvements in 
aging clocks in this species will lead to many discoveries both in the basis biology of aging and the discovery and validation of interventions that extend lifespan.

Additional models beyond the mouse may also be highly valuable, such as the naked mole rat with its extraordinary longevity compared to similar species [203]. Clocks have now been constructed in many animals, such as an estimator that can be used across both domestic dogs and wolves [204]. Variation identified within dog breeds with respect to aging is consistent with known lifespan differences [202]. The diverse range of wild animal clocks include, for instance, the humpback whale [205].

\section{Current uncertainty}

If DNA methylation clocks provide a readout of biological age, then it will be essential to determine its modifiability, whether or not therapeutic or lifestyle interventions will help to reverse it and gauge any impact on long-term health. The biological origins of the clock elicit a great deal of debate. Exploration will require experimentally and computationally deconvoluting the different processes of the clock into its constituent parts, where specific model organisms may have particular strengths. A broad variety of factors, beyond the clear role of genetics, are proposed in the dynamics of age-related methylation variation. These include inflammation, cell division, metabolic effects, cellular heterogeneity, diet, and a variety of other lifestyle factors, as well as stochastic effects. Regarding the possible involvement of metabolism, this is tightly intertwined with epigenetic regulation and nutrition specifically may modify DNA methylation [206], therefore pinpointing it as a potential significant mediator [207].

Further uncertainty arises from the obstacle that aging DNA methylation sites are only partially conserved among different mammalian species. Also, the inconsistent coverage from sequencing-based studies makes these less transferable, even across mouse experiments within the same tissue in the same strain. This technical issue with the reliance on sequencing, due to the lack of available commercial DNA methylation arrays in non-human species, reduces the utility of these published clocks.

\section{Future experiments and recommendations}

Construction of robust clocks in mammals and other vertebrates is likely to be highly informative for understanding aging. Mouse models have significant advantages due to their similar mammalian physiology, genomes, and epigenomes, but with a shorter lifespan, and ability to robustly control the animal environment. Most importantly, in contrast to human studies, direct genetic and pharmacological interventions can be more quickly tested in this species, although mouse aging experiments still take 3 years. So, for some questions, researchers can keep in mind the utility of short-lived vertebrate models with DNA methylation that are amenable to genetic manipulation, such as the killifish. Nevertheless, for consistent exploration of experimental clock modulation in mice, high-quality DNA methylome sequencing-based studies are needed. As mentioned in "Challenge 4," depth for high-quality DMP calling in humans is estimated at 100X [150]. While this requirement will not be quite as stringent in isogenic mice, low-coverage studies should be avoided, due to their inherent lack of power. Additionally, clocks constructed with alternate statistical methods that are more resilient to significant inherent stochastic loss of data points are also required, as discussed by Zhang et al. [46]. Additionally, human age DMP or DMR findings, in conserved genomic loci, can be explored in the mouse for further mechanistic insight. However, as detailed above, this focus obviously does not preclude the value of other aging models. Domestic animals, for example the dog, taking advantage of its genetic architecture and known age-related breed disease susceptibilities [208], may be an informative model for non-invasive longitudinal monitoring. Horvath is currently designing a pan-species array, with a reduced set of common probes, to facilitate a common clock measure across a range of organisms [209]. The identification of the target genes of epigenomic regulatory elements [210], such as enhancers or insulators modified by aging-related changes, may be highly informative and enable subsequent functional exploration in humans.

The use of non-invasive DNA methylation clocks in conservation and ecology is another highly valuable aspect that should be taken full advantage of. This was discussed recently regarding a novel chimpanzee-specific age estimator [211] and also relating to a range of wild animals [212]. The knowledge of the age of individual animals is extremely beneficial in animal conservation, facilitating more accurate estimations of demographics such as population age structure and reproductive success [212]. The study of humpback whales clearly displays the utility of DNA methylation clocks, as while they have similar lifespans to humans, these whales have no reliable visual age indicators after 1 year of age [205].

\section{Challenge 7}

Inclusion of epigenetics within current genetic ethical and legal frameworks

\section{Current knowledge}

Epigenetics is implicated in many facets of aging, and DNA methylation clocks provide a molecular readout of aspects of this underlying complexity [9]. The high correlation with chronological age has led to their use in forensics [54-56], although further proposals, such as age estimation in refugees [57], have significant ethical 
issues. As yet no policies exist governing the reporting of epigenetic findings or biological age estimates, including those based on DNA methylation. This current shortfall has been recognized for some time [213, 214]. To stimulate the necessary discussions, the first pioneering epigenetic reports including age estimates have been issued to study participants of the Personal Genome Project UK [215]. A comprehensive framework on the Ethical, Legal, and Social Implications (ELSI) is still required to be developed and formulated [216, 217]. Further illustrating the future of epigenomic analysis, distinct personal and multi-timepoint longitudinal DNA methylome changes were recently reported in an individual in relation to their chronic disease state [218].

\section{Current uncertainty}

Ambiguity surrounds the ethics of measuring biological aging, or aging modification by changes to lifestyle, and how personal responsibilities can be balanced against the requirements of society (e.g., insurance, provision of health care). Producing an objective and accurate surrogate marker for biological aging will reignite an age-old discussion concerning how, and to what extent, individuals can be held accountable for their own behavior and the impact this has on their health.

As detailed in the preceding sections, while the DNA methylation clocks provide novel and intriguing avenues for the biological exploration of the aging process, there remains a significant lack of knowledge regarding the accuracy and robustness of this broad-scale age estimator (see Table 1). This is particularly concerning when it is now being proposed for legal age verification or life insurance calculations. We currently do not know the validity of the various different clock measures in an individual, across populations, with respect to rare and common genetic variation, across time, or under particular environmental conditions, exposures or physiological changes.

\section{Future recommendations}

Safeguarding autonomous decision-making and how to obtain adequate informed consent in advance of calculating an individual's estimated biological age will require a complex framework, which has to be applicable for diverse circumstances. One set of measures will be required to cover obtaining consent from an individual who aims to attempt to decelerate "biological" aging by lifestyle change and wishes to use longitudinal analyses of a DNA methylation clock as a biofeedback marker. There will be a very different set of requirements for this personal monitoring, compared to more controversial societal and political issues, e.g., in the context of discrimination [219], socioeconomic circumstances, and migration. Using epigenetic data in an ELSI framework

Table 2 Summary of recommendations arising from the challenges of studying DNA methylation clocks in the context of aging

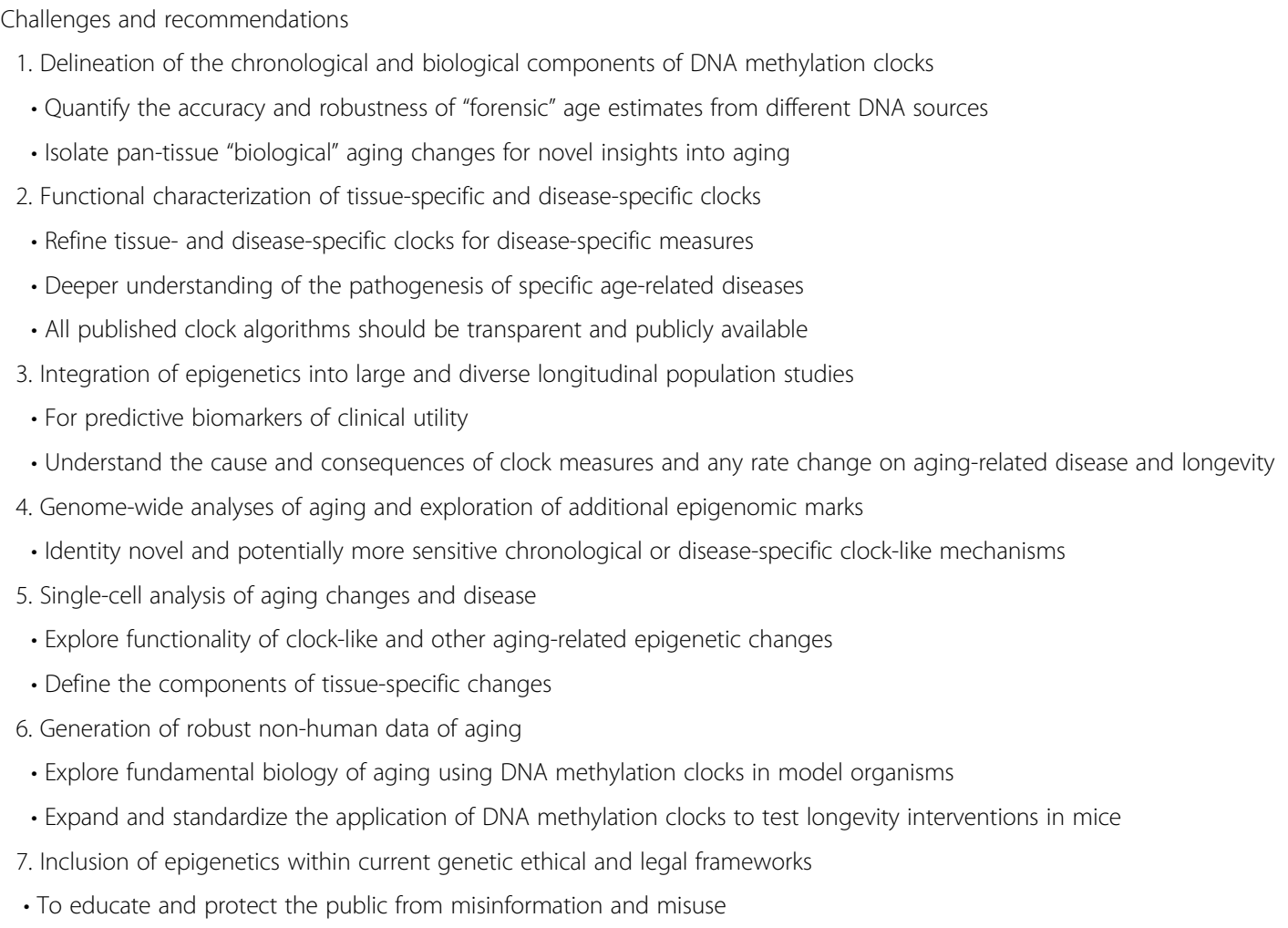


acceptable to all stakeholders will require transparent governance based on scientific accuracy, which will require significantly more rigorous scientific evaluation.

\section{Conclusion}

With this perspective, we have detailed seven challenges alongside the experiments and recommendations to explore these (summarized in Table 2), which we hope will help to further the fascinating biological discoveries that have accompanied DNA methylation clocks. These detailed strengths, weaknesses, and areas of inquiry should stimulate new discussion and experimentation.

The power of epigenomic analysis is clearly displayed by these precise aging-related changes. Detailed evaluation of DNA methylation clocks may reveal unique insights into the aging process itself, as well as act as a biomarker of biological age and inform on age-related common disease risk. While we have highlighted some caveats regarding the potential misuse of clocks, more detailed experiments should help to alleviate these. We have only begun to reap all of the insights that study of the epigenome will bring in deciphering physiology and pathology, and there is much promise for both improved human and animal health.

\section{Acknowledgements}

We apologize to our colleagues whose relevant work and original articles could not be cited owing to space constraints. We also thank Craig Nicol (Institute of Genetics and Molecular Medicine, University of Edinburgh) for his help in preparing the graphs displayed in Fig. 1a, c.

\section{Authors' contributions}

$C G B, R L$, and VKR co-ordinated the writing process. All authors participated in the planning and the writing of this review. All authors read and approved the final manuscript.

\section{Funding}

CGB received support from Diabetes UK (16/0005454). PDA is funded by the NIA (AG031862-12), NCl, and Glenn/AFAR. AAB is funded by the NIH (R01 ES025225, P30 ES009089, and R01 ES027747). SB is supported by the National Institute for Health Research (NIHR) UCLH Biomedical Research Centre (BRC369/CN/SB/101310). The views expressed are those of the author(s) and not necessarily those of the NIHR or the Department of Health and Social Care. JTB received support from the ESRC (ES/N000404/1) and JPI-HDHL through BBSRC (BB/S020845/1). BCC is funded by the NIH (CA216265). VNG is funded by NIH AG021518, AG047745, AG047200, and CA080946. BTH is funded by the Dutch Heart Foundation (2017T075), JPI HDHL (ZonMw 529051021), and BBMRI-NL (NWO 184.021.007 and 184.033.111). SH was supported by NIH/NIA U34AG051425-01. TI received funding from NIEHS R01ES014811. J-PJl is supported by NIH (CA214005, CA100632, and CA221705). KTK is funded by NIH (CA207360, CA216265, and CA207110) and PR0125 from the AACR. REM is supported by Alzheimer's Research UK (Grant ARUK-PG2017B-10). WR is supported by BBSRC (BB/K010867/1). CLR is a member of the Integrative Epidemiology Unit, which is supported by the Medical Research Council and the University of Bristol (MC_UU_12013/5), and she also receives funding from Cancer Research UK (Programme Grant C18281/A19169), the NIH (RO1Al121226, RO1MH113930, and RO1MDO1430401), the BBSRC (BB/P028187), and the ESRC (ESN000498/1). LCS is supported by MRC UK (MR/K013807/1 and MR/R005176/1). AET was supported by NSFC (National Science Foundation of China) grants (grant numbers 31571359 and 31771464) and by a Royal Society Newton Advanced Fellowship (NAF award number: 164914). WW is funded by the German Research Foundation (WA 1706/8-1), the Interdisciplinary Center for Clinical Research within the Faculty of Medicine at the RWTH Aachen University (O3-3),
Deutsche Krebshilfe (TRACK-AML), and the Federal Ministry of Education and Research (VIP + Epi-Blood-Count). VKR is supported by the BBSRC (BB/ R00675X/1).

\section{Competing interests}

The authors declare that they have no competing interests, except for the following: WW is a co-founder of Cygenia GmbH (www.cygenia.com), which may provide service for the epigenetic signatures; The Regents of the University of California is the sole owner of several patent applications directed at the invention of measures of epigenetic age estimation for which $\mathrm{SH}$ is a named inventor; and KTK is a founder and advisor to Cellintec, although Cellintec provided no support for, and had no role in, this work.

\section{Author details}

${ }^{1}$ William Harvey Research Institute, Barts and The London School of Medicine and Dentistry, Queen Mary University of London, London, UK. ${ }^{2}$ The Blizard Institute, Barts and The London School of Medicine and Dentistry, Queen Mary University of London, London, UK. ${ }^{3}$ Sanford Burnham Prebys Medical Discovery Institute, La Jolla, CA, USA. ${ }^{4}$ Beatson Institute for Cancer Research and University of Glasgow, Glasgow, UK. ${ }^{5}$ Department of Environmental Health Sciences, Mailman School of Public Health, Columbia University, New York, NY, USA. ' ${ }^{6}$ edical Genomics, Paul O'Gorman Building, UCL Cancer Institute, University College London, London, UK. ${ }^{7}$ Department of Twin Research and Genetic Epidemiology, King's College London, London, UK. ${ }^{8}$ Department of Epidemiology, Geisel School of Medicine, Dartmouth College, Lebanon, NH, USA. ${ }^{9}$ Department of Molecular and Systems Biology, Geisel School of Medicine, Dartmouth College, Lebanon, NH, USA.

${ }^{10}$ Department of Community and Family Medicine, Geisel School of Medicine, Dartmouth College, Lebanon, NH, USA. ${ }^{11}$ Division of Genetics, Department of Medicine, Brigham and Women's Hospital and Harvard Medical School, Boston, MA, USA. ${ }^{12}$ Molecular Epidemiology, Department of Biomedical Data Sciences, Leiden University Medical Center, Leiden, the Netherlands. ${ }^{13}$ Department of Human Genetics, Gonda Research Center, David Geffen School of Medicine, Los Angeles, CA, USA. ${ }^{14}$ Department of Biostatistics, School of Public Health, University of California-Los Angeles, Los Angeles, CA, USA. ${ }^{15}$ San Diego Center for Systems Biology, University of California-San Diego, San Diego, CA, USA. ${ }^{16}$ Fels Institute for Cancer Research, Lewis Katz School of Medicine, Temple University, Philadelphia, PA, USA. ${ }^{17}$ Department of Epidemiology, Brown University, Providence, RI, USA. ${ }^{18}$ Department of Pathology and Laboratory Medicine, Brown University, Providence, RI, USA. ${ }^{19} \mathrm{Centre}$ for Genomic and Experimental Medicine, Institute of Genetics and Molecular Medicine, University of Edinburgh, Edinburgh, UK. ${ }^{20}$ Centre for Cognitive Ageing and Cognitive Epidemiology, University of Edinburgh, Edinburgh, UK. ${ }^{21}$ Epigenetics Programme, The Babraham Institute, Cambridge, UK. ${ }^{22}$ The Wellcome Trust Sanger Institute, Cambridge, UK. ${ }^{23}$ Medical Research Council Integrative Epidemiology Unit (MRC IEU), School of Social and Community Medicine, University of Bristol, Bristol, UK. ${ }^{24}$ School of Biological Sciences, University of Essex, Colchester, UK. ${ }^{25}$ CAS Key Laboratory of Computational Biology, CAS-MPG Partner Institute for Computational Biology, Shanghai Institute of Nutrition and Health,

Shanghai Institutes for Biological Sciences, University of Chinese Academy of Sciences, Chinese Academy of Sciences, 320 Yue Yang Road, Shanghai 200031, China. ${ }^{26}$ UCL Cancer Institute, Paul O'Gorman Building, University College London, 72 Huntley Street, London WC1E 6BT, UK.

${ }^{27}$ Helmholtz-Institute for Biomedical Engineering, Stem Cell Biology and Cellular Engineering, RWTH Aachen Faculty of Medicine, Aachen, Germany.

${ }^{28}$ Faculty of Medicine, Macau University of Science and Technology, Taipa, Macau.

Received: 4 February 2019 Accepted: 16 September 2019

Published online: 25 November 2019

\section{References}

1. He W, Goodkind D, Kowal P. An aging world: 2015; 2016.

2. Partridge L, Deelen J, Slagboom PE. Facing up to the global challenges of ageing. Nature. 2018;561:45-56.

3. WHO: The world report on ageing and health. 2015.

4. Campisi J, Kapahi P, Lithgow GJ, Melov S, Newman JC, Verdin E. From discoveries in ageing research to therapeutics for healthy ageing. Nature. 2019:571:183-92. 
5. Christensen K, lachina M, Rexbye H, Tomassini C, Frederiksen H, McGue M, Vaupel JW. "Looking old for your age": genetics and mortality. Epidemiology. 2004;15:251-2.

6. Lopez-Otin C, Blasco MA, Partridge L, Serrano M, Kroemer G. The hallmarks of aging. Cell. 2013;153:1194-217.

7. Jylhävä J, Pedersen NL, Hägg S. Biological age predictors. EBioMedicine. 2017;21:29-36

8. Crimmins E, Vasunilashorn S, Kim JK, Alley D. Chapter 5 Biomarkers related to aging in human populations. In: Advances in clinical chemistry. Volume 46. San Diego: Elsevier; 2008. p. 161-216.

9. Horvath S, Raj K. DNA methylation-based biomarkers and the epigenetic clock theory of ageing. Nat Rev Genet. 2018;19:371-84.

10. Field AE, Robertson NA, Wang T, Havas A, Ideker T, Adams PD. DNA methylation clocks in aging: categories, causes, and consequences. Mol Cell. 2018;71:882-95.

11. Bird A. Perceptions of epigenetics. Nature. 2007:447:396-8.

12. Russo VEA, Riggs AD, Martienssen RA. Epigenetic mechanisms of gene regulation. Plainview: Cold Spring Harbor Laboratory Press; 1996.

13. Fraga MF, Esteller M. Epigenetics and aging: the targets and the marks Trends Genet. 2007;23:413-8.

14. Thompson RF, Fazzari MJ, Greally JM. Experimental approaches to the study of epigenomic dysregulation in ageing. Exp Gerontol. 2010;45:255-68.

15. Wilson $\mathrm{VL}$, Jones PA. DNA methylation decreases in aging but not in immortal cells. Science. 1983;220:1055-7.

16. Issa J-PJ, Ottaviano YL, Celano P, Hamilton SR, Davidson NE, Baylin SB. Methylation of the oestrogen receptor $\mathrm{CPG}$ island links ageing and neoplasia in human colon. Nat Genet. 1994;7:536-40.

17. Issa JP. Aging, DNA methylation and cancer. Crit Rev Oncol Hematol. 1999:32:31-43.

18. Teschendorff AE, Menon U, Gentry-Maharaj A, Ramus SJ, Weisenberger DJ, Shen H, Campan M, Noushmehr H, Bell CG, Maxwell AP, et al. Age-dependent DNA methylation of genes that are suppressed in stem cells is a hallmark of cancer. Genome Res. 2010;20:440-6.

19. Rakyan VK, Down TA, Maslau S, Andrew T, Yang TP, Beyan H, Whittaker P, McCann OT, Finer S, Valdes AM, et al. Human aging-associated DNA hypermethylation occurs preferentially at bivalent chromatin domains. Genome Res. 2010;20:434-9.

20. Christensen BC, Houseman EA, Marsit CJ, Zheng S, Wrensch MR, Wiemels JL, Nelson HH, Karagas MR, Padbury JF, Bueno R, et al. Aging and environmental exposures alter tissue-specific DNA methylation dependent upon CpG island context. PLoS Genet. 2009;5:e1000602.

21. Bocklandt S, Lin W, Sehl ME, Sanchez FJ, Sinsheimer JS, Horvath S, Vilain E. Epigenetic predictor of age. PLoS One. 2011;6:e14821.

22. Koch $C M$, Wagner $W$. Epigenetic-aging-signature to determine age in different tissues. Aging (Albany NY). 2011;3:1018-27.

23. Hannum G, Guinney J, Zhao L, Zhang L, Hughes G, Sadda S, Klotzle B, Bibikova M, Fan JB, Gao Y, et al. Genome-wide methylation profiles reveal quantitative views of human aging rates. Mol Cell. 2013;49:359-67.

24. Horvath S. DNA methylation age of human tissues and cell types. Genome Biol. 2013:14:R115.

25. Weidner Cl, Lin Q, Koch CM, Eisele L, Beier F, Ziegler P, Bauerschlag DO, Jockel $\mathrm{KH}$, Erbel R, Muhleisen TW, et al. Aging of blood can be tracked by DNA methylation changes at just three CpG sites. Genome Biol. 2014;15:R24.

26. Marioni RE, Shah S, McRae AF, Chen BH, Colicino E, Harris SE, Gibson J, Henders AK, Redmond P, Cox SR, et al. DNA methylation age of blood predicts all-cause mortality in later life. Genome Biol. 2015;16:25.

27. Chen BH, Marioni RE, Colicino E, Peters MJ, Ward-Caviness CK, Tsai PC, Roetker NS, Just AC, Demerath EW, Guan W, et al. DNA methylation-based measures of biological age: meta-analysis predicting time to death. Aging (Albany NY). 2016;8:1844-65.

28. Christiansen L, Lenart A, Tan Q, Vaupel JW, Aviv A, McGue M, Christensen K. DNA methylation age is associated with mortality in a longitudinal Danish twin study. Aging Cell. 2016;15:149-54.

29. Perna L, Zhang Y, Mons U, Holleczek B, Saum K-U, Brenner H. Epigenetic age acceleration predicts cancer, cardiovascular, and all-cause mortality in a German case cohort. Clin Epigenetics. 2016;8:64.

30. Tomasetti C, Vogelstein B. Cancer etiology. Variation in cancer risk among tissues can be explained by the number of stem cell divisions. Science. 2015;347:78-81.

31. Yang Z, Wong A, Kuh D, Paul DS, Rakyan VK, Leslie RD, Zheng SC, Widschwendter M, Beck S, Teschendorff AE. Correlation of an epigenetic mitotic clock with cancer risk. Genome Biol. 2016;17:205.
32. Horvath S, Erhart W, Brosch M, Ammerpohl O, von Schonfels W, Ahrens M, Heits N, Bell JT, Tsai PC, Spector TD, et al. Obesity accelerates epigenetic aging of human liver. Proc Natl Acad Sci U S A. 2014;111:15538-43.

33. Marioni RE, Shah S, McRae AF, Ritchie SJ, Muniz-Terrera G, Harris SE, Gibson J, Redmond P, Cox SR, Pattie A, et al. The epigenetic clock is correlated with physical and cognitive fitness in the Lothian Birth Cohort 1936. Int J Epidemiol. 2015;44(4):1388-96. https://doi.org/10.1093/ije/dyu277.

34. Levine ME, Lu AT, Bennett DA, Horvath S. Epigenetic age of the pre-frontal cortex is associated with neuritic plaques, amyloid load, and Alzheimer's disease related cognitive functioning. Aging (Albany NY). 2015;7:1198-211.

35. Horvath S, Ritz BR. Increased epigenetic age and granulocyte counts in the blood of Parkinson's disease patients. Aging (Albany NY). 2015;7:1130-42.

36. Levine ME, Lu AT, Chen BH, Hernandez DG, Singleton AB, Ferrucci L, Bandinelli S, Salfati E, Manson JE, Quach A, et al. Menopause accelerates biological aging. Proc Natl Acad Sci U S A. 2016;113:9327-32.

37. Quach A, Levine ME, Tanaka T, Lu AT, Chen BH, Ferrucci L, Ritz B, Bandinelli S, Neuhouser ML, Beasley JM, et al. Epigenetic clock analysis of diet, exercise, education, and lifestyle factors. Aging (Albany NY). 2017;9:419-46.

38. Nevalainen T, Kananen L, Marttila S, Jylhävä J, Mononen N, Kähönen M, Raitakari OT, Hervonen A, Jylhä M, Lehtimäki T, Hurme M. Obesity accelerates epigenetic aging in middle-aged but not in elderly individuals. Clin Epigenetics. 2017;9:20

39. Raina A, Zhao X, Grove ML, Bressler J, Gottesman RF, Guan W, Pankow JS, Boerwinkle E, Mosley TH, Fornage M. Cerebral white matter hyperintensities on MRI and acceleration of epigenetic aging: the atherosclerosis risk in communities study. Clin Epigenetics. 2017;9:21.

40. Zheng Y, Joyce BT, Colicino E, Liu L, Zhang W, Dai Q, Shrubsole MJ, Kibbe WA, Gao T, Zhang Z, et al. Blood epigenetic age may predict cancer incidence and mortality. EBioMedicine. 2016;5:68-73.

41. Gladyshev VN. Aging: progressive decline in fitness due to the rising deleteriome adjusted by genetic, environmental, and stochastic processes. Aging Cell. 2016;15:594-602.

42. Hughes A, Smart M, Gorrie-Stone T, Hannon E, Mill J, Bao Y, Burrage J, Schalkwyk L, Kumari M. Socioeconomic position and DNA methylation age acceleration across the life course. Am J Epidemiol. 2018;187:2346-54.

43. Levine ME, Lu AT, Quach A, Chen BH, Assimes TL, Bandinelli S, Hou L, Baccarelli AA, Stewart JD, Li Y, et al. An epigenetic biomarker of aging for lifespan and healthspan. Aging (Albany NY). 2018:10:573-91.

44. Zhang Y, Wilson R, Heiss J, Breitling LP, Saum KU, Schottker B, Holleczek B, Waldenberger $\mathrm{M}$, Peters $\mathrm{A}$, Brenner $\mathrm{H}$. DNA methylation signatures in peripheral blood strongly predict all-cause mortality. Nat Commun. 2017;8:14617.

45. Lu AT, Quach A, Wilson JG, Reiner AP, Aviv A, Raj K, Hou L, Baccarelli AA, Li Y, Stewart JD, et al. DNA methylation GrimAge strongly predicts lifespan and healthspan. Aging. 2019;11(2):303-327. https://doi.org/10.18632/aging.101684.

46. Zhang Q, Vallerga CL, Walker RM, Lin T, Henders AK, Montgomery GW, He J, Fan D, Fowdar J, Kennedy M, et al. Improved precision of epigenetic clock estimates across tissues and its implication for biological ageing. Genome Med. 2019:11:54.

47. Ecker S, Beck S. The epigenetic clock: a molecular crystal ball for human aging? Aging. 2019 Jan 21;11(2):833-5. https://doi.org/10.18632/aging.101712.

48. Peters MJ, Joehanes R, Pilling LC, Schurmann C, Conneely KN, Powell J, Reinmaa E, Sutphin GL, Zhernakova A, Schramm K, et al. The transcriptional landscape of age in human peripheral blood. Nat Commun. 2015;6:8570.

49. Belsky DW, Moffitt TE, Cohen AA, Corcoran DL, Levine ME, Prinz JA, Schaefer J, Sugden K, Williams B, Poulton R, Caspi A. Eleven telomere, epigenetic clock, and biomarker-composite quantifications of biological aging: do they measure the same thing? Am J Epidemiol. 2018;187:1220-30.

50. Kabacik S, Horvath $\mathrm{S}$, Cohen $\mathrm{H}$, Raj K. Epigenetic ageing is distinct from senescence-mediated ageing and is not prevented by telomerase expression. Aging (Albany NY). 2018;10:2800-15.

51. Lowe D, Horvath S, Raj K. Epigenetic clock analyses of cellular senescence and ageing. Oncotarget. 2016;7:8524-31.

52. Lu AT, Hannon E, Levine ME, Crimmins EM, Lunnon K, Mill J, Geschwind DH, Horvath S. Genetic architecture of epigenetic and neuronal ageing rates in human brain regions. Nat Commun. 2017:8:15353.

53. Lu AT, Seeboth A, Tsai PC, Sun D, Quach A, Reiner A, Kooperberg C, Ferrucci L, Hou L, Baccarelli A, et al. DNA methylation-based estimator of telomere length. Aging. 2019;11(16):5895-923. https://doi.org/10. 18632/aging.102173.

54. Yi SH, Xu LC, Mei K, Yang RZ, Huang DX. Isolation and identification of agerelated DNA methylation markers for forensic age-prediction. Forensic Science International: Genetics. 2014;11:117-25. 
55. Hwan Young L, Soong Deok L, Kyoung-Jin S. Forensic DNA methylation profiling from evidence material for investigative leads. BMB Rep. 2016; 49:359-69.

56. Vidaki A, Kayser M. From forensic epigenetics to forensic epigenomics: broadening DNA investigative intelligence. Genome Biol. 2017;18:238.

57. Abbott A. European scientists seek 'epigenetic clock' to determine age of refugees. Nature. 2018;561:15.

58. Jones MJ, Goodman SJ, Kobor MS. DNA methylation and healthy human aging. Aging Cell. 2015;14:924-32

59. Smeers I, Decorte R, Van de Voorde W, Bekaert B. Evaluation of three statistical prediction models for forensic age prediction based on DNA methylation. Forensic Sci Int Genet. 2018;34:128-33.

60. Booth Lauren N, Brunet A. The aging epigenome. Mol Cell. 2016;62:728-44

61. Luo C, Hajkova P, Ecker JR. Dynamic DNA methylation: in the right place at the right time. Science. 2018;361:1336-40.

62. Zhu T, Zheng SC, Paul DS, Horvath S, Teschendorff AE. Cell and tissue type independent age-associated DNA methylation changes are not rare but common. Aging. 2018;10:3541-57.

63. Slieker RC, Relton CL, Gaunt TR, Slagboom PE, Heijmans BT. Age-related DNA methylation changes are tissue-specific with ELOVL2 promoter methylation as exception. Epigenetics Chromatin. 2018;11:25.

64. Horvath S, Oshima J, Martin GM, Lu AT, Quach A, Cohen H, Felton S, Matsuyama M, Lowe D, Kabacik S, et al. Epigenetic clock for skin and blood cells applied to Hutchinson Gilford Progeria Syndrome and ex vivo studies. Aging (Albany NY). 2018;10:1758-75.

65. Genereux DP, Miner BE, Bergstrom CT, Laird CD. A population-epigenetic model to infer site-specific methylation rates from double-stranded DNA methylation patterns. Proc Natl Acad Sci U S A. 2005;102:5802-7.

66. Zhou W, Dinh HQ, Ramjan Z, Weisenberger DJ, Nicolet CM, Shen H, Laird PW, Berman BP. DNA methylation loss in late-replicating domains is linked to mitotic cell division. Nat Genet. 2018;50:591-602.

67. Gaidatzis D, Burger L, Murr R, Lerch A, Dessus-Babus S, Schübeler D, Stadler MB. DNA sequence explains seemingly disordered methylation levels in partially methylated domains of mammalian genomes. PLoS Genet. 2014:10:e1004143.

68. Cruickshanks HA, McBryan T, Nelson DM, Vanderkraats ND, Shah PP, van Tuyn J, Singh Rai T, Brock C, Donahue G, Dunican DS, et al. Senescent cells harbour features of the cancer epigenome. Nat Cell Biol. 2013;15:1495-506.

69. Baubec T, Colombo DF, Wirbelauer C, Schmidt J, Burger L, Krebs AR, Akalin A, Schubeler D. Genomic profiling of DNA methyltransferases reveals a role for DNMT3B in genic methylation. Nature. 2015;520(7546):243-7. https://doi. org/10.1038/nature14176

70. Martin-Herranz DE, Aref-Eshghi E, Bonder MJ, Stubbs TM, Choufani S, Weksberg R, Stegle O, Sadikovic B, Reik W, Thornton JM. Screening for genes that accelerate the epigenetic aging clock in humans reveals a role for the H3K36 methyltransferase NSD1. Genome Biol. 2019;20:146

71. Olova N, Simpson DJ, Marioni R, Chandra T. Partial reprogramming induces a steady decline in epigenetic age before loss of somatic identity. Aging Cell. 2019;18(1):e12877. https://doi.org/10.1111/acel.12877.

72. Sheng C, Jungverdorben J, Wiethoff $H$, Lin Q, Flitsch $L$, Eckert D, Hebisch M, Fischer J, Kesavan J, Weykopf B, et al. A stably self-renewing adult bloodderived induced neural stem cell exhibiting patternability and epigenetic rejuvenation. Nat Commun. 2018;9:4047

73. Bork S, Pfister S, Witt H, Horn P, Korn B, Ho AD, Wagner W. DNA methylation pattern changes upon long-term culture and aging of human mesenchymal stromal cells. Aging Cell. 2010;9:54-63.

74. Koch CM, Reck K, Shao K, Lin Q, Joussen S, Ziegler P, Walenda G, Drescher W, Opalka B, May T, et al. Pluripotent stem cells escape from senescenceassociated DNA methylation changes. Genome Res. 2013;23:248-59.

75. Frobel J, Rahmig S, Franzen J, Waskow C, Wagner W. Epigenetic aging of human hematopoietic cells is not accelerated upon transplantation into mice. Clin Epigenetics. 2018;10:67.

76. Stolzel F, Brosch M, Horvath S, Kramer M, Thiede C, von Bonin M, Ammerpohl O, Middeke M, Schetelig J, Ehninger G, et al. Dynamics of epigenetic age following hematopoietic stem cell transplantation. Haematologica. 2017;102:e321-3.

77. Søraas A, Matsuyama M, de Lima M, Wald D, Buechner J, Gedde-Dahl T, Søraas C, Chen B, Ferrucci L, Dahl J, et al. Epigenetic age is a cell-intrinsic property in transplanted human hematopoietic cells. Aging Cell. 2019;18(2): e12897. https://doi.org/10.1111/acel.12897.

78. Jones A, Teschendorff AE, Li Q, Hayward JD, Kannan A, Mould T, West J Zikan M, Cibula D, Fiegl H, et al. Role of DNA methylation and epigenetic silencing of HAND2 in endometrial cancer development. PLoS Med. 2013;10: e1001551.

79. Alisch RS, Barwick BG, Chopra P, Myrick LK, Satten GA, Conneely KN, Warren ST. Age-associated DNA methylation in pediatric populations. Genome Res. 2012;22:623-32

80. Martino D, Loke YJ, Gordon L, Ollikainen M, Cruickshank MN, Saffery R, Craig JM. Longitudinal, genome-scale analysis of DNA methylation in twins from birth to 18 months of age reveals rapid epigenetic change in early life and pair-specific effects of discordance. Genome Biol. 2013;14:R42.

81. Feil R, Fraga MF. Epigenetics and the environment: emerging patterns and implications. Nat Rev Genet. 2011;13:97-109.

82. Yuan T, Jiao Y, de Jong S, Ophoff RA, Beck S, Teschendorff AE. An integrative multi-scale analysis of the dynamic DNA methylation landscape in aging. PLoS Genet. 2015;11:e1004996

83. Lu T, Aron L, Zullo J, Pan Y, Kim H, Chen Y, Yang TH, Kim HM, Drake D, Liu $X S$, et al. REST and stress resistance in ageing and Alzheimer's disease. Nature. 2014;507:448-54.

84. Reynolds LM, Taylor JR, Ding J, Lohman K, Johnson C, Siscovick D, Burke G, Post W, Shea S, Jacobs DR Jr, et al. Age-related variations in the methylome associated with gene expression in human monocytes and t cells. Nat Commun. 2014:5:5366. https://doi.org/10.1038/ncomms6366.

85. Teschendorff AE, West J, Beck S. Age-associated epigenetic drift: implications, and a case of epigenetic thrift? Hum Mol Genet. 2013;4:4.

86. Bonder MJ, Luijk R, Zhernakova DV, Moed M, Deelen P, Vermaat M, van Iterson M, van Dijk F, van Galen M, Bot J, et al. Disease variants alter transcription factor levels and methylation of their binding sites. Nat Genet. 2017:49:131-8.

87. Schubeler D. Function and information content of DNA methylation. Nature. 2015;517:321-6.

88. Hu S, Wan J, Su Y, Song Q, Zeng Y, Nguyen HN, Shin J, Cox E, Rho HS, Woodard C, et al. DNA methylation presents distinct binding sites for human transcription factors. Elife. 2013;2:e00726.

89. Domcke S, Bardet AF, Adrian Ginno P, Hartl D, Burger L, Schubeler D. Competition between DNA methylation and transcription factors determines binding of NRF1. Nature. 2015;528:575-9.

90. Yin Y, Morgunova E, Jolma A, Kaasinen E, Sahu B, Khund-Sayeed S, Das PK, Kivioja T, Dave K, Zhong F, et al. Impact of cytosine methylation on DNA binding specificities of human transcription factors. Science. 2017;356(6337): eaj2239. https://doi.org/10.1126/science.aaj2239.

91. Fernandez AF, Assenov $Y$, Martin-Subero Jl, Balint B, Siebert $R$, Taniguchi $H$, Yamamoto H, Hidalgo M, Tan AC, Galm O, et al. A DNA methylation fingerprint of 1628 human samples. Genome Res. 2012;22:407-19.

92. Cole JJ, Robertson NA, Rather MI, Thomson JP, McBryan T, Sproul D, Wang $T$, Brock C, Clark W, Ideker T, et al. Diverse interventions that extend mouse lifespan suppress shared age-associated epigenetic changes at critical gene regulatory regions. Genome Biol. 2017;18:58.

93. Rulands S, Lee HJ, Clark SJ, Angermueller C, Smallwood SA, Krueger F, Mohammed H, Dean W, Nichols J, Rugg-Gunn P, et al. Genome-scale oscillations in DNA methylation during exit from pluripotency. Cell Systems. 2018;7:63-76. e12

94. Wu H, Zhang Y. Reversing DNA methylation: mechanisms, genomics, and biological functions. Cell. 2014;156:45-68.

95. Wallis SJ, Wall J, Biram RW, Romero-Ortuno R. Association of the clinica frailty scale with hospital outcomes. QJM. 2015;108:943-9.

96. Farré $\mathrm{P}$, Jones MJ, Meaney MJ, Emberly E, Turecki G, Kobor MS. Concordant and discordant DNA methylation signatures of aging in human blood and brain. Epigenetics Chromatin. 2015:8:19.

97. Teschendorff AE. Epigenetic clocks galore: a new improved clock predicts age-acceleration in Hutchinson Gilford Progeria Syndrome patients. Aging 2018;10(8):1799-800. https://doi.org/10.18632/aging.101533.

98. Youn A, Wang S. The MiAge Calculator: a DNA methylation-based mitotic age calculator of human tissue types. Epigenetics. 2018;13:192-206.

99. Hamidouche Z, Rother K, Przybilla J, Krinner A, Clay D, Hopp L, Fabian C, Stolzing A, Binder H, Charbord P, Galle J. Bistable epigenetic states explain age-dependent decline in mesenchymal stem cell heterogeneity. Stem Cells. 2017:35:694-704

100. Przybilla J, Rohlf T, Loeffler M, Galle J. Understanding epigenetic changes in aging stem cells--a computational model approach. Aging Cell. 2014:13:320-8.

101. Marioni RE, Suderman M, Chen BH, Horvath S, Bandinelli S, Morris T, Beck S, Ferrucci L, Pedersen NL, Relton $\mathrm{CL}$, et al. Tracking the epigenetic clock across the human life course: a meta-analysis of longitudinal cohort data. J 
Gerontol A Biol Sci Med Sci. 2019;74(1):57-61. https://doi.org/10.1093/ gerona/gly060.

102. Horvath S, Gurven M, Levine ME, Trumble BC, Kaplan H, Allayee H, Ritz BR, Chen B, Lu AT, Rickabaugh TM, et al. An epigenetic clock analysis of race/ ethnicity, sex, and coronary heart disease. Genome Biol. 2016;17:171.

103. Simpkin AJ, Hemani G, Suderman M, Gaunt TR, Lyttleton O, McArdle WL, Ring SM, Sharp GC, Tilling K, Horvath S, et al. Prenatal and early life influences on epigenetic age in children: a study of mother-offspring pairs from two cohort studies. Hum Mol Genet. 2016;25:191-201.

104. Simpkin AJ, Howe LD, Tilling K, Gaunt TR, Lyttleton O, McArdle WL, Ring SM, Horvath S, Smith GD, Relton CL. The epigenetic clock and physical development during childhood and adolescence: longitudinal analysis from a UK birth cohort. Int J Epidemiol. 2017;46(2):549-58. https://doi.org/10.1093/ije/dyw307.

105. Hannon E, Knox O, Sugden K, Burrage J, Wong CCY, Belsky DW, Corcoran DL, Arseneault L, Moffitt TE, Caspi A, Mill J. Characterizing genetic and environmental influences on variable DNA methylation using monozygotic and dizygotic twins. PLoS Genet. 2018;14:e1007544.

106. Gaunt TR, Shihab HA, Hemani G, Min JL, Woodward G, Lyttleton O, Zheng J, Duggirala A, McArdle WL, Ho K, et al. Systematic identification of genetic influences on methylation across the human life course. Genome Biol. 2016;17:61.

107. van Dongen J, Nivard MG, Willemsen G, Hottenga JJ, Helmer Q, Dolan CV, Ehli EA, Davies GE, van Iterson M, Breeze CE, et al. Genetic and environmental influences interact with age and sex in shaping the human methylome. Nat Commun. 2016;7:11115.

108. Bell CG, Gao F, Yuan W, Roos L, Acton RJ, Xia Y, Bell J, Ward K, Mangino M, Hysi PG, et al. Obligatory and facilitative allelic variation in the DNA methylome within common disease-associated loci. Nat Commun. 2018;9:8.

109. Zhang Q, Marioni RE, Robinson MR, Higham J, Sproul D, Wray NR, Deary IJ, McRae AF, Visscher PM. Genotype effects contribute to variation in longitudinal methylome patterns in older people. Genome Medicine. 2018;10:75.

110. Lu AT, Xue L, Salfati EL, Chen BH, Ferrucci L, Levy D, Joehanes R, Murabito JM, Kiel DP, Tsai P-C, et al. GWAS of epigenetic ageing rates in blood reveals a critical role for TERT. Nat Commun. 2018;9(1):387. https://doi.org/10.1038/ s41467-017-02697-5.

111. Slieker RC, van Iterson M, Luijk R, Beekman M, Zhernakova DV, Moed MH, Mei $\mathrm{H}$, van Galen M, Deelen P, Bonder MJ, et al. Age-related accrual of methylomic variability is linked to fundamental ageing mechanisms. Genome Biol. 2016;17:191.

112. Wang Y, Pedersen NL, Hägg S. Implementing a method for studying longitudinal DNA methylation variability in association with age. Epigenetics. 2018;13(8):866-74. https://doi.org/10.1080/15592294.2018.1521222.

113. El Khoury LY, Gorrie-Stone T, Smart M, Hughes A, Bao Y, Andrayas A, Burrage J, Hannon E, Kumari M, Mill J, Schalkwyk LC. Properties of the epigenetic clock and age acceleration. bioRxiv. 2018;363143. https://doi.org/ 10.1101/363143.

114. Moskowitz DM, Zhang DW, Hu B, Le Saux S, Yanes RE, Ye Z, Buenrostro JD, Weyand CM, Greenleaf WJ, Goronzy JJ. Epigenomics of human CD8 T cell differentiation and aging. Sci Immunol. 2017;2(8):eaag0192. https://doi.org/ 10.1126/sciimmunol.aag0192.

115. Alpert A, Pickman Y, Leipold M, Rosenberg-Hasson Y, Ji X, Gaujoux R, Rabani $H$, Starosvetsky E, Kveler K, Schaffert S, et al. A clinically meaningful metric of immune age derived from high-dimensional longitudinal monitoring. Nat Med. 2019:25:487-95.

116. Khera AV, Chaffin M, Aragam KG, Haas ME, Roselli C, Choi SH, Natarajan P, Lander ES, Lubitz SA, Ellinor PT, Kathiresan S. Genome-wide polygenic scores for common diseases identify individuals with risk equivalent to monogenic mutations. Nat Genet. 2018;50:1219-24.

117. Torkamani A, Wineinger NE, Topol EJ. The personal and clinical utility of polygenic risk scores. Nat Rev Genet. 2018;19(9):581-90. https://doi.org/10. 1038/s41576-018-0018-x.

118. Relton CL, Gaunt T, McArdle W, Ho K, Duggirala A, Shihab H, Woodward G, Lyttleton O, Evans DM, Reik W, et al. Data resource profile: Accessible Resource for Integrated Epigenomic Studies (ARIES). Int J Epidemiol. 2015;44:1181-90.

119. Mendelson MM, Marioni RE, Joehanes R, Liu C, Hedman AK, Aslibekyan S, Demerath EW, Guan W, Zhi D, Yao C, et al. Association of body mass index with DNA methylation and gene expression in blood cells and relations to cardiometabolic disease: a Mendelian randomization approach. PLoS Med. 2017:14:e1002215.

120. Relton CL, Davey Smith G. Two-step epigenetic Mendelian randomization: a strategy for establishing the causal role of epigenetic processes in pathways to disease. Int J Epidemiol. 2012;41:161-76.
121. Relton CL, Davey Smith G. Mendelian randomization: applications and limitations in epigenetic studies. Epigenomics. 2015;7:1239-43.

122. Zheng J, Erzurumluoglu AM, Elsworth BL, Kemp JP, Howe L, Haycock PC, Hemani G, Tansey K, Laurin C, Pourcain BS, et al. LD Hub: a centralized database and web interface to perform LD score regression that maximizes the potential of summary level GWAS data for SNP heritability and genetic correlation analysis. Bioinformatics. 2017;33:272-9.

123. Shah S, Bonder MJ, Marioni RE, Zhu Z, McRae AF, Zhernakova A, Harris SE, Liewald D, Henders AK, Mendelson MM, et al. Improving phenotypic prediction by combining genetic and epigenetic associations. Am J Hum Genet. 2015;97:75-85.

124. McCartney DL, Hillary RF, Stevenson AJ, Ritchie SJ, Walker RM, Zhang Q, Morris SW, Bermingham ML, Campbell A, Murray AD, et al. Epigenetic prediction of complex traits and death. Genome Biol. 2018;19:136.

125. Joehanes $R$, Just $A C$, Marioni RE, Pilling $L C$, Reynolds $L M$, Mandaviya $P R$, Guan W, Xu T, Elks CE, Aslibekyan S, et al. Epigenetic signatures of cigarette smoking. Circ Cardiovasc Genet. 2016;9:436-47.

126. Bojesen SE, Timpson N, Relton C, Davey Smith G, Nordestgaard BG. AHRR (cg05575921) hypomethylation marks smoking behaviour, morbidity and mortality. Thorax. 2017;72:646-53.

127. Hindorff LA, Bonham VL, Brody LC, Ginoza MEC, Hutter CM, Manolio TA, Green ED. Prioritizing diversity in human genomics research. Nat Rev Genet. 2017;19:175.

128. van Dongen J, Slagboom PE, Draisma HH, Martin NG, Boomsma DI. The continuing value of twin studies in the omics era. Nat Rev Genet. 2012; 13:640-53.

129. Poulain M, Herm A, Pes G. The Blue Zones: areas of exceptional longevity around the world. Vienna Yearbook of Population Research. 2013;11:87-108.

130. Hoffman MM, Ernst J, Wilder SP, Kundaje A, Harris RS, Libbrecht M, Giardine $B$, Ellenbogen PM, Bilmes JA, Birney E, et al. Integrative annotation of chromatin elements from ENCODE data. Nucleic Acids Res. 2013:41:827-41.

131. Quinlan AR, Hall IM. BEDTools: a flexible suite of utilities for comparing genomic features. Bioinformatics. 2010;26:841-2.

132. Harrow J, Frankish A, Gonzalez JM, Tapanari E, Diekhans M, Kokocinski F. GENCODE: the reference human genome annotation for The ENCODE Project. Genome Res. 2012;22(9):1760-74. https://doi.org/10.1101/gr.135350.111.

133. Karolchik D, Barber GP, Casper J, Clawson H, Cline MS, Diekhans M. The UCSC Genome Browser database: 2014 update. Nucleic Acids Res. 2014; 42(Database issue):D764-70. https://doi.org/10.1093/nar/gkt1168.

134. Baubec T, Schübeler D. Genomic patterns and context specific interpretation of DNA methylation. Curr Opin Genet Dev. 2014;25:85-92.

135. Hodges E, Molaro A, Dos Santos CO, Thekkat P, Song Q, Uren PJ, Park J, Butler J, Rafii S, McCombie WR, et al. Directional DNA methylation changes and complex intermediate states accompany lineage specificity in the adult hematopoietic compartment. Mol Cell. 2011;44:17-28.

136. Irizarry RA, Ladd-Acosta C, Wen B, Wu Z, Montano C, Onyango P, Cui H, Gabo K, Rongione M, Webster M, et al. The human colon cancer methylome shows similar hypo- and hypermethylation at conserved tissuespecific CpG island shores. Nat Genet. 2009;41:178-86.

137. Ziller MJ, Gu H, Muller F, Donaghey J, Tsai LT, Kohlbacher O, De Jager PL, Rosen ED, Bennett DA, Bernstein BE, et al. Charting a dynamic DNA methylation landscape of the human genome. Nature. 2013;500:477-81.

138. Schultz MD, He Y, Whitaker JW, Hariharan M, Mukamel EA, Leung D, Rajagopal $\mathrm{N}$, Nery JR, Urich MA, Chen $\mathrm{H}$, et al. Human body epigenome maps reveal noncanonical DNA methylation variation. Nature. 2015;523:212-6.

139. Xiong J, Jiang HP, Peng CY, Deng QY, Lan MD, Zeng H, Zheng F, Feng YQ, Yuan BF. DNA hydroxymethylation age of human blood determined by capillary hydrophilic-interaction liquid chromatography/mass spectrometry. Clin Epigenetics. 2015;7:72.

140. Benayoun BA, Pollina EA, Brunet A. Epigenetic regulation of ageing: linking environmental inputs to genomic stability. Nat Rev Mol Cell Biol. 2015;16:593.

141. Thomson JP, Skene PJ, Selfridge J, Clouaire T, Guy J, Webb S, Kerr AR, Deaton A, Andrews R, James KD, et al. CpG islands influence chromatin structure via the CpG-binding protein Cfp1. Nature. 2010;464:1082-6.

142. Blackledge NP, Zhou JC, Tolstorukov MY, Farcas AM, Park PJ, Klose RJ. CpG islands recruit a histone H3 lysine 36 demethylase. Mol Cell. 2010;38:179-90.

143. Soria-Valles C, Osorio FG, López-Otín C. Reprogramming aging through DOT1L inhibition. Cell cycle (Georgetown, Tex). 2015;14:3345-6.

144. Peleg S, Sananbenesi F, Zovoilis A, Burkhardt S, Bahari-Javan S, Agis-Balboa RC, Cota P, Wittnam JL, Gogol-Doering A, Opitz L, et al. Altered histone acetylation is associated with age-dependent memory impairment in mice. Science. 2010;328:753-6. 
145. Stefanelli G, Azam AB, Walters BJ, Brimble MA, Gettens CP, BouchardCannon P, Cheng HM, Davidoff AM, Narkaj K, Day JJ, et al. Learning and age-related changes in genome-wide $\mathrm{H} 2 \mathrm{~A} . \mathrm{Z}$ binding in the mouse hippocampus. Cell Rep. 2018;22:1124-31.

146. Klein H-U, McCabe C, Gjoneska E, Sullivan SE, Kaskow BJ, Tang A, Smith RV, Xu J, Pfenning AR, Bernstein BE, et al. Epigenome-wide study uncovers tau pathology-driven changes of chromatin organization in the aging human brain. Nat Neurosci. 2019;22(1):37-46. https://doi.org/10.1038/s41593-0180291-1.

147. Heyn H, Li N, Ferreira HJ, Moran S, Pisano DG, Gomez A, Diez J, SanchezMut JV, Setien F, Carmona FJ, et al. Distinct DNA methylomes of newborns and centenarians. Proc Natl Acad Sci U S A. 2012;109:10522-7.

148. McClay JL, Aberg KA, Clark SL, Nerella S, Kumar G, Xie LY, Hudson AD, Harada A, Hultman CM, Magnusson PK, et al. A methylome-wide study of aging using massively parallel sequencing of the methyl-CpG-enriched genomic fraction from blood in over 700 subjects. Hum Mol Genet. 2014:23:1175-85.

149. Bell CG, Xia Y, Yuan W, Gao F, Ward K, Roos L, Mangino M, Hysi PG, Bell J, Wang J, Spector TD. Novel regional age-associated DNA methylation changes within human common disease-associated loci. Genome Biol. 2016;17:193.

150. Libertini E, Heath SC, Hamoudi RA, Gut M, Ziller MJ, Herrero J, Czyz A, Ruotti V, Stunnenberg $\mathrm{HG}$, Frontini $M$, et al. Saturation analysis for whole-genome bisulfite sequencing data. Nat Biotechnol. 2016; https:/doi.org/10.1038/nbt.3524.

151. Chuong EB, Elde NC, Feschotte C. Regulatory activities of transposable elements: from conflicts to benefits. Nat Rev Genet. 2017:18:71-86.

152. Ward MC, Wilson MD, Barbosa-Morais NL, Schmidt D, Stark R, Pan Q, Schwalie PC, Menon S, Lukk M, Watt S, et al. Latent regulatory potential of human-specific repetitive elements. Mol Cell. 2012;12:00944-6.

153. Blattler A, Yao L, Witt H, Guo Y, Nicolet CM, Berman BP, Farnham PJ. Global loss of DNA methylation uncovers intronic enhancers in genes showing expression changes. Genome Biol. 2014;15:469.

154. Gaudet F, Hodgson JG, Eden A, Jackson-Grusby L, Dausman J, Gray JW, Leonhardt $\mathrm{H}$, Jaenisch R. Induction of tumors in mice by genomic hypomethylation. Science. 2003;300:489-92.

155. Deniz Ö, Frost JM, Branco MR. Regulation of transposable elements by DNA modifications. Nat Rev Genet. 2019;20(7):432. https://doi.org/10.1038/ s41576-019-0117-3.

156. Chen Y-A, Lemire M, Choufani S, Butcher DT, Grafodatskaya D, Zanke BW, Gallinger S, Hudson TJ, Weksberg R. Discovery of cross-reactive probes and polymorphic CpGs in the Illumina Infinium HumanMethylation450 microarray. Epigenetics. 2013;8:203-9.

157. Leung D, Jung I, Rajagopal N, Schmitt A, Selvaraj S, Lee AY, Yen CA, Lin S, Lin Y, Qiu Y, et al. Integrative analysis of haplotype-resolved epigenomes across human tissues. Nature. 2015:518:350-4.

158. Estecio MR, Gallegos J, Vallot C, Castoro RJ, Chung W, Maegawa S, Oki Y, Kondo $Y$, Jelinek J, Shen L, et al. Genome architecture marked by retrotransposons modulates predisposition to DNA methylation in cancer. Genome Res. 2010;20:1369-82.

159. Maegawa S, Hinkal G, Kim HS, Shen L, Zhang L, Zhang J, Zhang N, Liang S, Donehower LA, Issa JP. Widespread and tissue specific age-related DNA methylation changes in mice. Genome Res. 2010;20:332-40.

160. Estecio MR, Gallegos J, Dekmezian M, Lu Y, Liang S, Issa JP. SINE retrotransposons cause epigenetic reprogramming of adjacent gene promoters. Mol Cancer Res. 2012;10:1332-42.

161. Wu X, Zhang Y. TET-mediated active DNA demethylation: mechanism, function and beyond. Nat Rev Genet. 2017;18(9):517-34. https://doi.org/10. 1038/nrg.2017.33.

162. Zhang Y, Hapala J, Brenner H, Wagner W. Individual CpG sites that are associated with age and life expectancy become hypomethylated upon aging. Clin Epigenetics. 2017;9:9.

163. Maierhofer A, Flunkert J, Oshima J, Martin GM, Haaf T, Horvath S. Accelerated epigenetic aging in Werner syndrome. Aging (Albany NY) 2017:9:1143-52

164. Zhang W, Li J, Suzuki K, Qu J, Wang P, Zhou J, Liu X, Ren R, Xu X, Ocampo A, et al. Aging stem cells. A Werner syndrome stem cell model unveils heterochromatin alterations as a driver of human aging. Science. 2015;348:1160-3.

165. Sun W, Poschmann J, Cruz-Herrera Del Rosario R, Parikshak NN, Hajan HS, Kumar V, Ramasamy R, Belgard TG, Elanggovan B, Wong CC, et al. Histone acetylome-wide association study of autism spectrum disorder. Cell. 2016; 167:1385-97. e1311
166. Lunnon K, Hannon E, Smith RG, Dempster E, Wong C, Burrage J, Troakes C, Al-Sarraj S, Kepa A, Schalkwyk L, Mill J. Variation in 5-hydroxymethylcytosine across human cortex and cerebellum. Genome Biol. 2016;17:27.

167. Schutsky EK, DeNizio JE, Hu P, Liu MY, Nabel CS, Fabyanic EB, Hwang Y, Bushman FD, Wu H, Kohli RM. Nondestructive, base-resolution sequencing of 5-hydroxymethylcytosine using a DNA deaminase. Nat Biotechnol. 2018; 36:1083-90. https://doi.org/10.1038/nbt.4204.

168. Korbie D, Lin E, Wall D, Nair SS, Stirzaker C, Clark SJ, Trau M. Multiplex bisulfite PCR resequencing of clinical FFPE DNA. Clin Epigenetics. 2015;7:28.

169. Bahar R, Hartmann CH, Rodriguez KA, Denny AD, Busuttil RA, Dolle ME, Calder RB, Chisholm GB, Pollock BH, Klein CA, Vijg J. Increased cell-tocell variation in gene expression in ageing mouse heart. Nature. 2006; 441:1011-4

170. Rimmelé P, Bigarella Carolina L, Liang R, Izac B, Dieguez-Gonzalez R, Barbet G, Donovan M, Brugnara C, Blander Julie M, Sinclair David A, Ghaffari S. Aging-like phenotype and defective lineage specification in SIRT1-deleted hematopoietic stem and progenitor cells. Stem Cell Reports. 2014;3:44-59.

171. Lappalainen T, Greally JM. Associating cellular epigenetic models with human phenotypes. Nat Rev Genet. 2017;18:441-51.

172. Kelsey G, Stegle $O$, Reik W. Single-cell epigenomics: recording the past and predicting the future. Science. 2017;358:69-75.

173. Montoro DT, Haber AL, Biton M, Vinarsky V, Lin B, Birket SE, Yuan F, Chen S, Leung HM, Villoria J, et al. A revised airway epithelial hierarchy includes CFTR-expressing ionocytes. Nature. 2018;560:319-24.

174. Baar MP, Brandt RMC, Putavet DA, Klein JDD, Derks KWJ, Bourgeois BRM, Stryeck S, Rijksen $Y$, van Willigenburg H, Feijtel DA, et al. Targeted apoptosis of senescent cells restores tissue homeostasis in response to chemotoxicity and aging. Cell. 2017;169:132-47. e116

175. Angermueller C, Lee HJ, Reik W, Stegle O. DeepCpG: accurate prediction of single-cell DNA methylation states using deep learning. Genome Biol. 2017;18:67.

176. Hernando-Herraez I, Evano B, Stubbs T, Commere P-H, Clark S, Andrews S, Tajbakhsh S, Reik W. Ageing affects DNA methylation drift and transcriptional cell-to-cell variability in muscle stem cells. Nat Commun. 2019;10(1):4361. https://doi.org/10.1038/s41467-019-12293-4.

177. Cheung P, Vallania F, Warsinske HC, Donato M, Schaffert S, Chang SE, Dvorak M, Dekker CL, Davis MM, Utz PJ, et al. Single-cell chromatin modification profiling reveals increased epigenetic variations with aging. Cell. 2018;173:1385-97. e1314

178. Martinez-Jimenez CP, Eling N, Chen H-C, Vallejos CA, Kolodziejczyk AA, Connor F, Stojic L, Rayner TF, Stubbington MJT, Teichmann SA, et al. Aging increases cell-to-cell transcriptional variability upon immune stimulation. Science. 2017;355:1433-6.

179. Jaiswal S, Fontanillas P, Flannick J, Manning A, Grauman PV, Mar BG, Lindsley RC, Mermel CH, Burtt N, Chavez A, et al. Age-related clonal hematopoiesis associated with adverse outcomes. N Engl J Med. 2014;371:2488-98.

180. Genovese G, Kähler AK, Handsaker RE, Lindberg J, Rose SA, Bakhoum SF, Chambert K, Mick E, Neale BM, Fromer M, et al. Clonal hematopoiesis and blood-cancer risk inferred from blood DNA sequence. N Engl J Med. 2014 371:2477-87.

181. Jaiswal S, Natarajan P, Silver AJ, Gibson CJ, Bick AG, Shvartz E, McConkey M, Gupta N, Gabriel S, Ardissino D, et al. Clonal hematopoiesis and risk of atherosclerotic cardiovascular disease. N Engl J Med. 2017:377:111-21.

182. Declerck K, Vanden Berghe W. Back to the future: epigenetic clock plasticity towards healthy aging. Mech Ageing Dev. 2018;174:18-29.

183. MacParland SA, Liu JC, Ma XZ, Innes BT, Bartczak AM, Gage BK, Manuel J, Khuu N, Echeverri J, Linares I, et al. Single cell RNA sequencing of human liver reveals distinct intrahepatic macrophage populations. Nat Commun. 2018:9:4383.

184. Martincorena I, Fowler JC, Wabik A, Lawson ARJ, Abascal F, Hall MWJ, Cagan A, Murai K, Mahbubani K, Stratton MR, et al. Somatic mutant clones colonize the human esophagus with age. Science. 2018;362(6417):911-7. https://doi. org/10.1126/science.aau3879.

185. Lodato MA, Rodin RE, Bohrson CL, Coulter ME, Barton AR, Kwon M, Sherman MA, Vitzthum CM, Luquette LJ, Yandava CN, et al. Aging and neurodegeneration are associated with increased mutations in single human neurons. Science. 2018;359:555-9.

186. Lee MH, Siddoway B, Kaeser GE, Segota I, Rivera R, Romanow WJ, Liu CS, Park C, Kennedy G, Long T, Chun J. Somatic APP gene recombination in Alzheimer's disease and normal neurons. Nature. 2018; 563:639-45 
187. Plass C, Pfister SM, Lindroth AM, Bogatyrova O, Claus R, Lichter P. Mutations in regulators of the epigenome and their connections to global chromatin patterns in cancer. Nat Rev Genet. 2013;14:765-80.

188. Clark SJ, Argelaguet R, Kapourani CA, Stubbs TM, Lee HJ, Alda-Catalinas C, Krueger F, Sanguinetti G, Kelsey G, Marioni JC, et al. scNMT-seq enables joint profiling of chromatin accessibility DNA methylation and transcription in single cells. Nat Commun. 2018;9:781.

189. Regev A, Teichmann SA, Lander ES, Amit I, Benoist C, Birney E, Bodenmille B, Campbell P, Carninci P, Clatworthy M, et al. The Human Cell Atlas. eLife. 2017:6:e27041.

190. Cao J, Cusanovich DA, Ramani V, Aghamirzaie D, Pliner HA, Hill AJ, Daza RM, McFaline-Figueroa JL, Packer JS, Christiansen L, et al. Joint profiling of chromatin accessibility and gene expression in thousands of single cells. Science. 2018;361(6409):1380-5. https://doi.org/10.1126/science.aau0730.

191. Shema E, Bernstein BE, Buenrostro JD. Single-cell and single-molecule epigenomics to uncover genome regulation at unprecedented resolution. Nat Genet. 2019;51(1):19-25. https://doi.org/10.1038/s41588-018-0290-x.

192. Gujar H, Liang JW, Wong NC, Mozhui K. Profiling DNA methylation differences between inbred mouse strains on the Illumina Human Infinium MethylationEPIC microarray. PLoS One. 2018;13:e0193496.

193. Sziraki A, Tyshkovskiy A, Gladyshev VN. Global remodeling of the mouse DNA methylome during aging and in response to calorie restriction. Aging Cell. 2018;17:e12738.

194. Maegawa S, Lu Y, Tahara T, Lee JT, Madzo J, Liang S, Jelinek J, Colman RJ, Issa JJ. Caloric restriction delays age-related methylation drift. Nat Commun. 2017;8:539.

195. Maegawa S, Gough SM, Watanabe-Okochi N, Lu Y, Zhang N, Castoro RJ, Estecio MR, Jelinek J, Liang S, Kitamura T, et al. Age-related epigenetic drift in the pathogenesis of MDS and AML. Genome Res. 2014;24:580-91.

196. Stubbs TM, Bonder MJ, Stark AK, Krueger F, Team BIAC, von Meyenn F, Stegle O, Reik W. Multi-tissue DNA methylation age predictor in mouse. Genome Biol. 2017;18:68.

197. Thompson MJ, Chwialkowska K, Rubbi L, Lusis AJ, Davis RC, Srivastava A Korstanje R, Churchill GA, Horvath S, Pellegrini M. A multi-tissue full lifespan epigenetic clock for mice. Aging (Albany NY). 2018;10:2832-54.

198. Meer MV, Podolskiy DI, Tyshkovskiy A, Gladyshev VN. A whole lifespan mouse multi-tissue DNA methylation clock. eLife. 2018;7:e40675.

199. Wang T, Tsui B, Kreisberg JF, Robertson NA, Gross AM, Yu MK, Carter H, Brown-Borg HM, Adams PD, Ideker T. Epigenetic aging signatures in mice livers are slowed by dwarfism, calorie restriction and rapamycin treatment. Genome Biol. 2017;18:57.

200. Petkovich DA, Podolskiy DI, Lobanov AV, Lee SG, Miller RA, Gladyshev VN. Using DNA methylation profiling to evaluate biological age and longevity interventions. Cell Metab. 2017:25:954-60. e956

201. Oh G, Ebrahimi S, Carlucci M, Zhang A, Nair A, Groot DE, Labrie V, Jia P, Oh ES, Jeremian $\mathrm{RH}$, et al. Cytosine modifications exhibit circadian oscillations that are involved in epigenetic diversity and aging. Nat Commun. 2018;9:644.

202. Lowe R, Barton C, Jenkins CA, Ernst C, Forman O, Fernandez-Twinn DS, Bock C, Rossiter SJ, Faulkes CG, Ozanne SE, et al. Ageing-associated DNA methylation dynamics are a molecular readout of lifespan variation among mammalian species. Genome Biol. 2018;19:22.

203. Tan L, Ke Z, Tombline G, Macoretta N, Hayes K, Tian X, Lv R, Ablaeva J, Gilbert $M$, Bhanu NV, et al. Naked mole rat cells have a stable epigenome that resists iPSC reprogramming. Stem Cell Reports. 2017:9:1721-34.

204. Thompson MJ, von Holdt B, Horvath S, Pellegrini M. An epigenetic aging clock for dogs and wolves. Aging. 2017:9:1055-68.

205. Polanowski AM, Robbins J, Chandler D, Jarman SN. Epigenetic estimation of age in humpback whales. Mol Ecol Resour. 2014;14:976-87.

206. Lempradl A, Pospisilik JA, Penninger JM. Exploring the emerging complexity in transcriptional regulation of energy homeostasis. Nat Rev Genet. 2015;16:665-81.

207. Hahn O, Gronke S, Stubbs TM, Ficz G, Hendrich O, Krueger F, Andrews S, Zhang Q, Wakelam MJ, Beyer A, et al. Dietary restriction protects from ageassociated DNA methylation and induces epigenetic reprogramming of lipid metabolism. Genome Biol. 2017;18:56.

208. Lequarré A-S, Andersson L, André C, Fredholm M, Hitte C, Leeb T, Lohi H, Lindblad-Toh K, Georges M. LUPA: a European initiative taking advantage of the canine genome architecture for unravelling complex disorders in both human and dogs. Vet J. 2011;189:155-9.

209. Horvath S. Epigenetic clocks: from molecular pathways to anti-aging interventions. In: Epigenomics of Common Disease 2017. Hinxton, Cambridge; 2017. p. S73.
210. Whalen S, Truty RM, Pollard KS. Enhancer-promoter interactions are encoded by complex genomic signatures on looping chromatin. Nat Genet. 2016;48:488-96.

211. Ito $\mathrm{H}$, Udono $\mathrm{T}$, Hirata $\mathrm{S}$, Inoue-Murayama M. Estimation of chimpanzee age based on DNA methylation. Sci Rep. 2018;8:9998.

212. De Paoli-lseppi R, Deagle BE, McMahon CR, Hindell MA, Dickinson JL, Jarman SN. Measuring animal age with DNA methylation: from humans to wild animals. Front Genet. 2017;8:106. https://doi.org/10.3389/fgene.2017.00106

213. Dyke SO, Cheung WA, Joly Y, Ammerpohl O, Lutsik P, Rothstein MA, Caron M, Busche $S$, Bourque $G$, Ronnblom L, et al. Epigenome data release: a participantcentered approach to privacy protection. Genome Biol. 2015;16:142.

214. Carter AC, Chang HY, Church G, Dombkowski A, Ecker JR, Gil E, Giresi PG, Greely $\mathrm{H}$, Greenleaf WJ, Hacohen N, et al. Challenges and recommendations for epigenomics in precision health. Nat Biotechnol. 2017;35:1128-32.

215. PGP-UK Consortium. Personal Genome Project UK (PGP-UK): a research and citizen science hybrid project in support of personalized medicine. BMC Med Genet. 2018;11:108.

216. Levesque E, Kirby E, Bolt I, Knoppers BM, de Beaufort I, Pashayan N, Widschwendter M. Ethical, legal, and regulatory issues for the implementation of omics-based risk prediction of women's cancer: points to consider. Public Health Genomics. 2018;21(1-2):37-44. https://doi.org/10 1159/000492663.

217. Dyke SO, Saulnier KM, Dupras C, Procaccini D, Webster AP, Maschke K, Rothstein MA, Siebert R, Walter J, Beck S, et al. Points-to-consider on the return of results in epigenetic research. Genome Med. 2019;11:31. https:// doi.org/10.1186/s13073-019-0646-6.

218. Chen R, Xia L, Tu K, Duan M, Kukurba K, Li-Pook-Than J, Xie D, Snyder M. Longitudinal personal DNA methylome dynamics in a human with a chronic condition. Nat Med. 2018 Dec;24(12):1930-9. https://doi.org/10. 1038/s41591-018-0237-x

219. Dupras C, Song L, Saulnier KM, Joly Y. Epigenetic discrimination: emerging applications of epigenetics pointing to the limitations of policies against genetic discrimination. Front Genet. 2018;9:202.

\section{Publisher's Note}

Springer Nature remains neutral with regard to jurisdictional claims in published maps and institutional affiliations. 